\title{
Cone penetration testing in thinly inter-layered soils
}

\section{Toon I. Van der Linden MSC}

Geotechnical Engineer, Royal HaskoningDHV, Amersfoort, the Netherlands; Former Department of Geo-Engineering, Delft University of Technology, Delft, the Netherlands (corresponding author: toon.van.der.linden@rhdhv. com; toonvdl@gmail.com)

Dirk A. De Lange MSc

Geotechnical researcher/consultant, Deltares, Delft, The Netherlands
Mandy Korff MSC, PhD

Senior Specialist, Deltares, Delft, the Netherlands; Associate Professor, Department of Geo-Engineering, Delft University of Technology, Delft, the Netherlands

The effect of a soft layer on the cone resistance of a sand layer has been studied extensively, but the same cannot be said for the case of multi-layered deposits with many (thin) alternating soil layers. For geotechnical analyses based on cone penetration test data it is difficult to estimate a representative value of the cone resistance when encountering alternating thin layers of clay or peat and sand. This paper presents physical modelling tests to understand the 'value' of the cone resistance in thinly multi-layered soil deposits. The test results are compared with existing analytical methods. It is concluded that the characteristic resistance of the individual layers, the layer thicknesses relative to the cone diameter and the number of layers within the zone of influence of the cone affect the cone resistance in deposits containing multiple thin soil layers. Suggestions for practical implementation are also given.

\section{Notation}

$c_{\mathrm{u}} \quad$ undrained shear strength $(\mathrm{kPa})$

$D_{\text {eq }} \quad$ equivalent pile diameter $(\mathrm{m})$

$d_{\text {cone }} \quad$ cone diameter $(\mathrm{mm})$

$H \quad$ (thin) layer thickness (mm)

$I_{\mathrm{D}} \quad$ density index

$K_{0} \quad$ coefficient of lateral earth pressure

$K_{\mathrm{H}} \quad$ thin-layer correction factor

$K_{\mathrm{t}} \quad$ correction factor for cone resistance in multiple thin sand layers

$p_{\mathrm{a}} \quad$ atmospheric pressure $(\mathrm{kPa})$

$q_{\mathrm{b}, \max } \quad$ maximum pile tip resistance (MPa)

$q_{\mathrm{c}} \quad$ measured cone resistance (MPa)

$q_{\mathrm{c}}^{*} \quad$ characteristic cone resistance (MPa)

$q_{\text {c,char,clay }}$ characteristic cone resistance in clay

$q_{\text {c,char,sand }}$ characteristic cone resistance in sand

$q_{\text {c,max,layer maximum cone resistance in a layer }}$

$q_{\text {c,norm } \quad \text { normalised cone resistance }}$

$R_{\mathrm{f}} \quad$ friction ratio

$S$

factor accounting for cross-sectional shape of the pile base

$u_{2} \quad$ pore pressure

w water content

$Z \quad$ depth (mm)

$\alpha_{\mathrm{p}} \quad$ pile class factor

$\beta \quad$ pile base shape factor

$\sigma_{\mathrm{m}}^{\prime} \quad$ mean effective stress $(\mathrm{kPa})$

$\sigma_{\mathrm{v}}^{\prime} \quad$ effective vertical stress $(\mathrm{kPa})$

\section{Introduction}

Cone penetration testing (CPT) is widely used to determine the geotechnical engineering properties of soils and delineate soil stratigraphy. The resolution of CPT in delineating stratigraphic layers is related to the size of the cone tip and the friction sleeve and the sample recording related to the penetration rate. A transition zone can be defined around the interface between two different soil layers, since the cone resistance will be affected by both the underlying and overlying layers. The dimensions of such a transition zone are a function of the cone tip size. Interpretation of CPT within these intervals carries large uncertainty, especially for deposits containing multiple thin layers, because the cone resistance will be affected by several surrounding layers.

This study focuses on the cone resistance of sand layers in socalled 'flaser beds'. These are sedimentary bedding patterns created when sediment is deposited by intermittent flows, leading to alternating sand and clay layers. Such deposits typically exist in marine environments (Martin, 2000; Reineck and Wunderlich, 1968). Figure 1 shows an example of a sediment core containing such depositional features. The sand layers typically have a thickness of $5 \mathrm{~mm}$ to several centimetres. CPT (Figure 2) was undertaken adjacent to this sediment core: the location of the flaser bed deposit is marked by the dashed rectangle on the CPT plot. CPT measurements were logged at $2 \mathrm{~cm}$ intervals of penetration. Cone resistances of 1-2 MPa were measured within this bed. The pore pressure deviated somewhat from the hydrostatic line and a friction ratio of about $2 \%$ was found in this region. The soil was classified as clayey silt to silty clay and sandy silt to clayey silt, based on the classification method of Robertson et al. (1986).

When CPT data are used to estimate liquefaction potential, Idriss and Boulanger (2008) noted that CPT values need to be corrected for transition zones between clay and sand. It is also conceivable that a better understanding of CPT in thinly layered soils is desired for other applications. Flaser beds can 


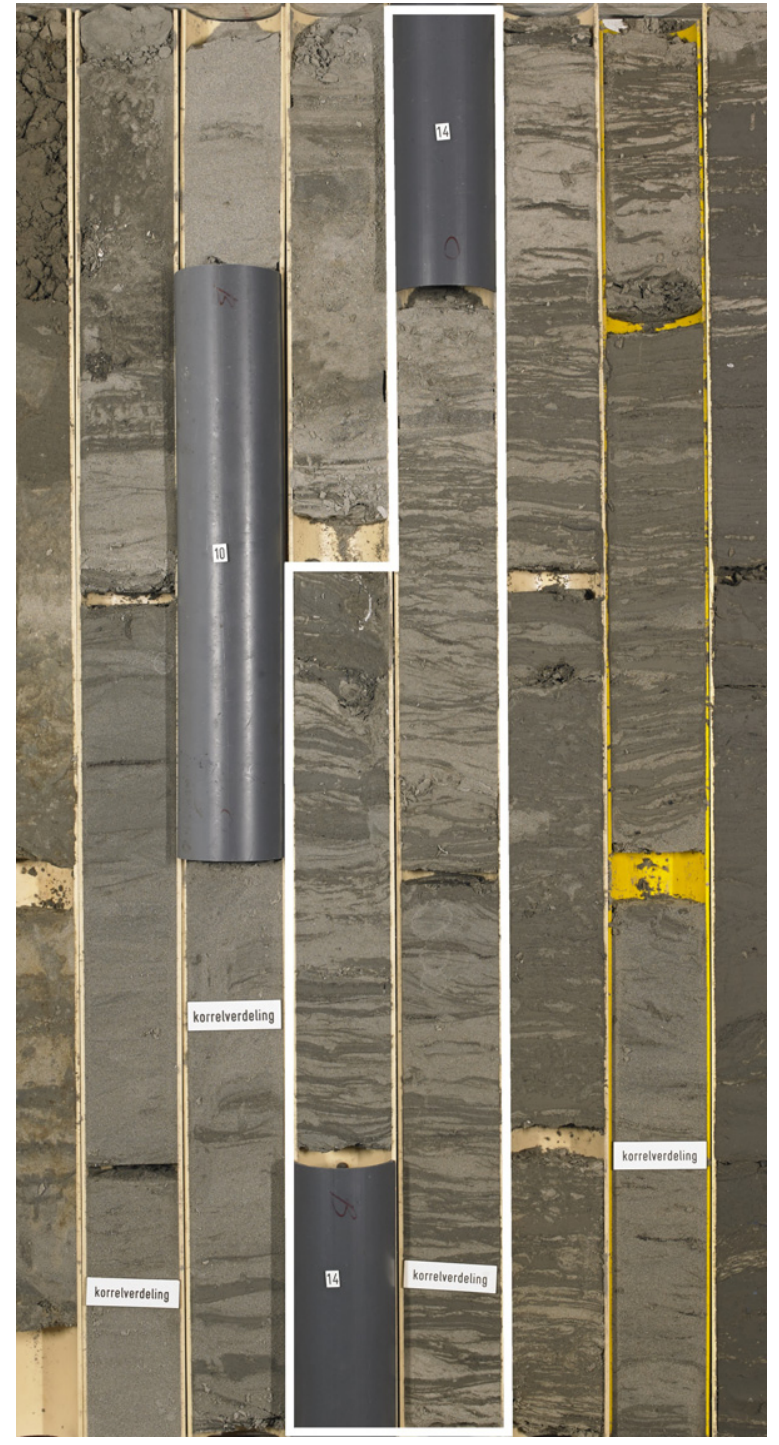

Figure 1. Sediment core with flaser bed sedimentation between depths of 4.5 and $6 \mathrm{~m}$ marked in white (each core sample was taken over a depth of $1 \mathrm{~m}$ )

easily be mischaracterised as clean sand, which, given the low cone resistances measured, gives a false (too high) indication of the liquefaction potential. Using CPT data measured in flaser bed deposits can have implications for determination of the stress state (e.g. by using the classification method of Robertson (1990)) or the shear strength and the density index (e.g. using the method of Baldi et al. (1986)). Current methods for correction of thin layers are based on analytical linear elastic solutions (e.g. Joer et al., 1996; Robertson and Fear, 1995; Vreugdenhil et al., 1994) or numerical analysis of single intermediate layers only (Ahmadi and Robertson, 2005).

This paper presents the results of a feasibility study undertaken to devise a correction method to determine more realistic engineering properties of thin sand layers within thinly interlayered zones. The measured cone resistance needs to be converted to a 'clean sand' resistance, hereafter referred to as characteristic resistance. CPT was performed in artificially constructed deposits containing multiple soil layers and the test results were compared with existing analytical solutions for this problem. Thin layers are defined as layers thinner than the diameter of the penetrometer.

\section{CPT and layered soils}

According to De Beer (1963), one of the most important factors that determines the magnitude of cone resistance is the dimensions of the failure wedge around the tip during penetration. The shape and size of this wedge depend on the cone tip size, soil strength parameters and effective stresses (Prandtl, 1921). For frictional materials such as sands, the failure surfaces typically have a logarithmic spiral form while, for clays, the form of the failure surface is considered to be more circular and smaller than the surface forms in sand (Meyerhof, 1951). In homogeneous soils, these shapes can be distinguished well (e.g. Arshad et al., 2014) but in soils with thin alternating layers the shape of the failure surface cannot be easily differentiated. This makes qualitative determination of the cone resistance in alternating thin layers using failure surface analysis complex.

\subsection{Existing physical models for CPT in thinly layered soil}

For sediment profiles containing sand layers with different characteristics, the effects of layering on cone resistance have been studied extensively (Joer et al., 1996; Młynarek et al., 2012; Mo, 2014; Silva and Bolton, 2004; Van den Berg, 1994).

From tests containing two layers (clay on sand and sand on clay), Van den Berg (1994) concluded that a cone penetrating in frictional material is influenced by an underlying soft clay layer at a distance of four to five times the cone diameter. Silva and Bolton (2004) performed piezocone tests on sand samples containing layers with different grain size fractions but having the same density index. They concluded that the effect of an underlying soil layer could be identified when the cone approaches the layer boundary at a distance of three cone diameters. Xu (2007) and $\mathrm{Xu}$ and Lehane (2008) concluded, based on jacked pile tests in a centrifuge, that pile base resistance is affected at a greater distance from the layer interface when the underlying layer is softer than when the underlying layer is stiffer than the considered layer. From the tests conducted, $\mathrm{Xu}$ (2007) found that the distance of influence varies between three and eight times the base diameter, depending on the ratio between the characteristic resistances in the stiff and soft soil layers. Van den Berg (1994) and Mo (2014) also concluded that the size of the transition zone depends on the stiffness ratio between the layers or the density index of both layers.

Van den Berg (1994) concluded that about six to seven times the cone diameter of penetration is needed to reach the full 


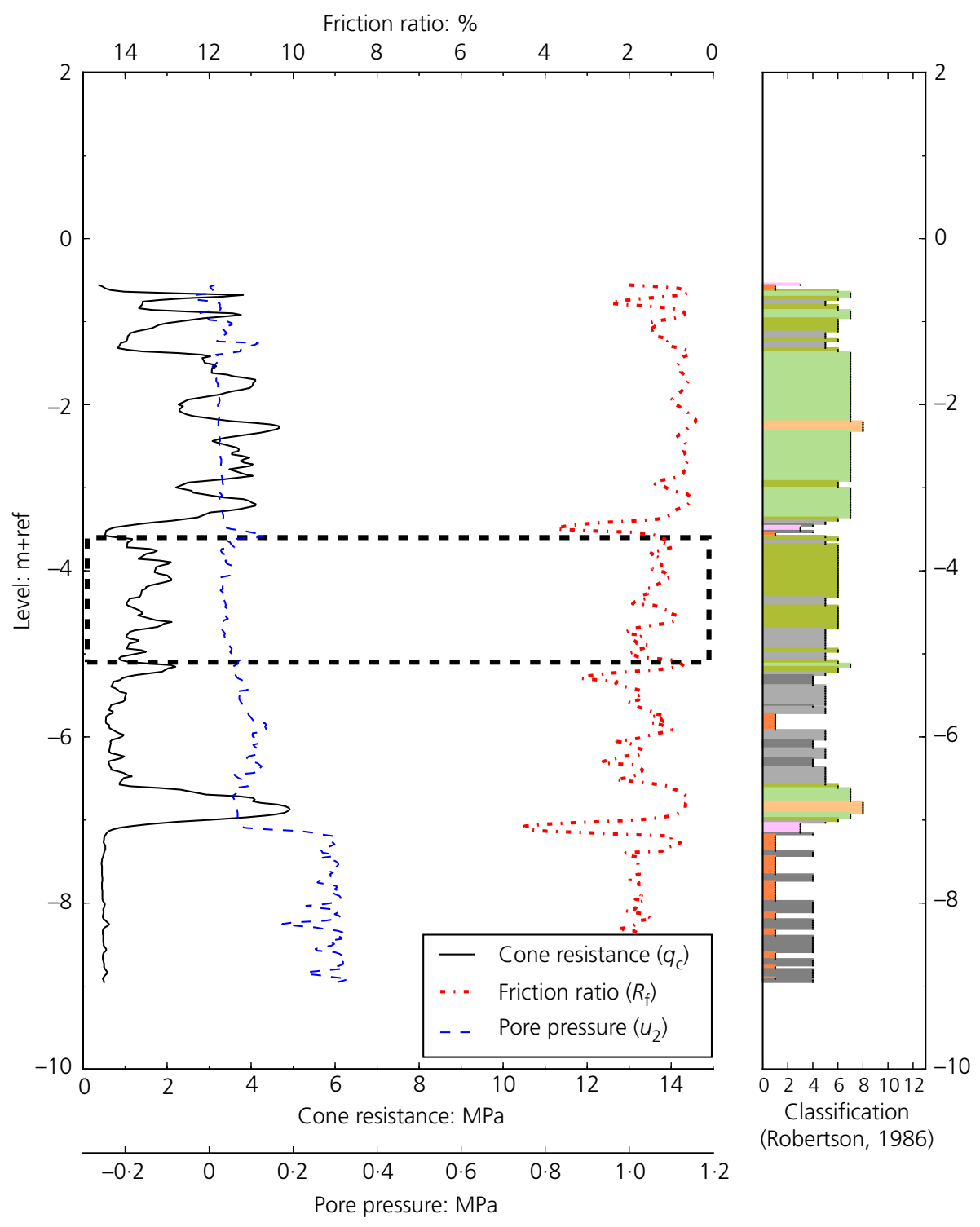

Figure 2. Example of cone penetration results in flaser beds undertaken close to the sediment core shown in Figure 1. A full-colour version of this figure can be found on the ICE Virtual Library (www.icevirtuallibrary.com)

steady-state cone resistance in a frictional layer, while research conducted by Joer et al. (1996), consisting of penetration tests in layered cemented soil surrounded by rigid boundaries, using a $3 \mathrm{~mm}$ dia. probe and a $10 \mathrm{~mm}$ dia. cone, showed that a penetration of 12 times the cone diameter and 25 times the probe diameter was needed to reach the characteristic resistance. Both Xu (2007) and Van den Berg (1994) found that as the pile or cone penetrometer enters the clay layer, the cone resistance reduces rapidly to the characteristic resistance of clay.

Mo (2014) and Mo et al. (2015) performed CPT on two- and three-layered soil samples. In the case of the three-layer system with a single stiffer 'thin' layer, it was concluded that when the density index of the 'thin' layer increased, the maximum resistance measured in the thin layer reduced relative to the characteristic sand resistance. This means that, for thin layers, the difference between the measured and the characteristic cone resistance increases with increasing density index and is not only affected by the layer thickness.

\subsection{Existing work on numerical modelling of thin layers}

Based on the linear elastic solution proposed by Vreugdenhil et al. (1994), who argued that cone resistance is affected elastically by the presence of a nearby layer, Robertson and Fear (1995) proposed the parameter $K_{\mathrm{H}}$ to correct the cone resistance to a characteristic value. $K_{\mathrm{H}}$ is defined as the factor by which the maximum measured cone resistance of a laminated 
layer needs to be multiplied to obtain the equivalent thicklayer cone resistance. The equation given for $K_{\mathrm{H}}$ was presented for a standard cone having a cross-sectional area of $10 \mathrm{~cm}^{2}$. Youd and Idriss (2001) presented a range of field data related to the correction parameter $K_{\mathrm{H}}$ (from unpublished work by Robertson and Castro) and, from this, proposed a more conservative equation because the field data indicated that $K_{\mathrm{H}}$ was being overestimated. They also stated that the correction proposed by Robertson and Fear (1995) applies only to 'thin' stiff layers embedded within thick soft layers.

Ahmadi and Robertson (2005) applied a numerical modelling procedure to predict the cone resistance of an intermediate sand layer embedded within soft clay. The modelling procedure was verified with published experimental results of calibration chamber tests carried out by Ahmadi (2000) and the displacement pattern obtained from the performed numerical analysis was similar to that of the experimental observations of Van den Berg (1994). Ahmadi and Robertson (2005) showed that the in situ stress state can have a significant effect on the cone resistance measured in a single sand layer within a soft soil. The in situ stress state also influences the distance to the layer interface at which the cone resistance is influenced by the following layer.

Van den Berg et al. (1996) also found that the distance over which a cone is affected by a neighbouring layer depends strongly on the stiffness ratio of the two layers, based on Eulerian finite-element modelling.

Walker and Yu (2010) modelled CPT in multi-layered clays using an explicit finite-element method with an adaptive mesh. They found that when the cone passed from a weak layer to a strong layer, the change in measured resistance was abrupt, whereas when the cone proceeded from a strong layer to a weak layer, the penetration resistance was significantly affected on both sides of the layer interface.

Mo et al. (2017) presented results of analytical cavity expansion solutions. By first analysing two-layered models, a simple superposition method of the two-layered problem was applied to the analysis of penetration in multi-layered soils. The analysis of the CPT data in two-layered soils highlighted the effect of strength and stiffness on CPT measurements within the influence zones around a two-soil interface. The effect of a single thin layer was studied and a correction factor for 'thin' layers was proposed that fitted well with the field data reported by Youd and Idriss (2001).

All the research mentioned thus far focused on two- or threelayered systems and did not consider thin layers, which are defined as layers of smaller thickness than the diameter of the penetrometer. The research presented in this paper aimed to investigate thinly inter-layered soils containing five or more alternating sand and clay layers. For multi-layer systems, it is expected that the cone resistance would be influenced by the layer thickness (relative to the cone diameter), the number of layers within the zone of influence and the characteristic cone resistances of the individual layers, which depend, among other things, on the porosity and the stress level.

\section{Physical model tests}

Physical model tests were performed in order to derive and validate an analytical method that is able to translate the measured cone resistance in thin-layered soil to the characteristic cone resistance, focusing on the cone resistance of the thin sand layers. Seven soil models were prepared to investigate the suitability of the proposed test set-up. CPT was performed on saturated layered soil deposits that were artificially built up in a cylindrical container. Four different layering configurations were tested. In this paper, four tests are presented, representing each of these configurations.

\subsection{Test set-up}

The test set-up consisted of a hydraulic plunger fixed on a reaction frame that was able to push a miniature cone into a cylinder containing the artificially built-up soil deposits. The cylindrical container was made from separate steel rings of inner diameter $600 \mathrm{~mm}$. The container height was $1.024 \mathrm{~m}$ for test 2 and was $1.255 \mathrm{~m}$ for the other tests reported in this paper. The plunger had a stroke of $1 \mathrm{~m}$ and CPT was performed in the centre of the container. A cone of diameter $25 \mathrm{~mm}$ (cross-sectional area of $5 \mathrm{~cm}^{2}$ ) containing a friction sleeve of length $94 \mathrm{~mm}$ and a pore pressure $\left(u_{2}\right)$ transducer mounted on the shoulder of the cone was applied to minimise possible boundary effects. The container/cone diameter ratio was thus 24, which is in general considered to be sufficient for sands having a (relatively) low density index (Ahmadi and Robertson, 2004; Bolton et al., 1999). A displacement transducer was used to determine the penetration depth of the cone. Figure 3 shows the container and the test set-up for test 7 .

\subsection{Soil model}

\subsubsection{Configurations}

Table 1 shows the characteristics of the selected tests. Test 2 contained a clay layer of $300 \mathrm{~mm}$ thickness between two sand layers each having a bulk density index of $92 \%$. For the initial soil models, a high density index was applied in the sand layers to speed up sample preparation: in this way less sample disturbance was expected due to placing of the clay layers. However, it was found that a lower density index had to be applied to the sand layers in order to avoid boundary effects. Therefore, a bulk density index of around $55 \%$ was applied to the sand layers in the later soil models. Test 5 contained a layered unit of three clay and two sand layers, each $80 \mathrm{~mm}$ thick. Test 6 contained a layered unit of ten clay and nine sand layers, each $20 \mathrm{~mm}$ thick. The layered units were sandwiched between two sand layers having the same density index. Test 7 consisted of sand only in order to measure the characteristic 
Cone penetration testing in thinly

inter-layered soils

Van der Linden, De Lange and Korff

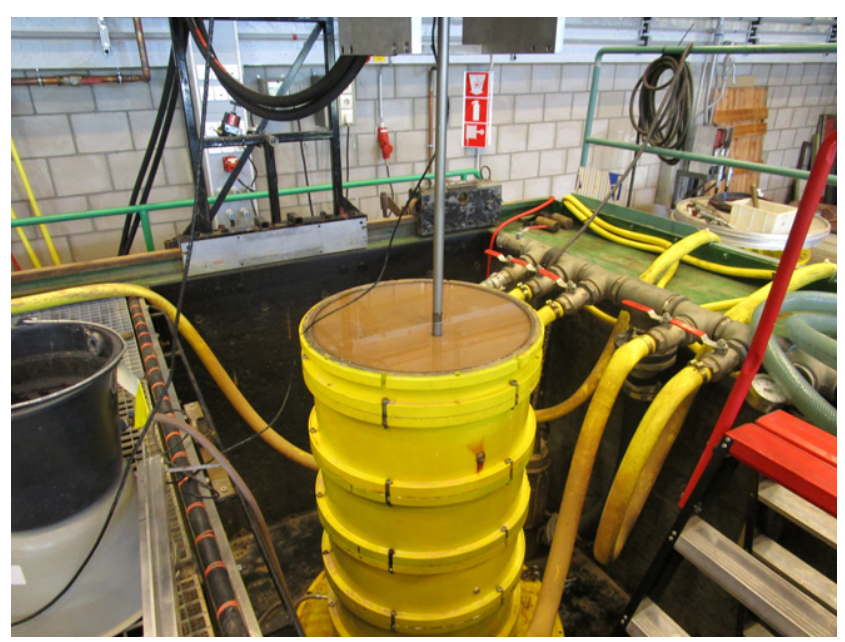

Figure 3. Test set-up (steel tank with sand sample, test 7)

value of the sand with a density index of around $55 \%$ and test 2 was used to determine the characteristic value of the clay layers. Figure 4 shows the sample configurations of each test.

\subsubsection{Soil materials}

Baskarp sand and Vingerling clay (pottery/brick clay delivered by Sibelco, type K147) were used to create the (layered) soil deposits. Tables 2 and 3 list some characteristics of both materials. The sieving characteristics of the Baskarp sand were obtained from two samples, while the minimum and maximum void ratios were determined using multiple sand samples. For every brick of clay delivered, the undrained shear strength and water content were measured. The undrained shear strength was measured by means of pocket penetrometer testing. Table 3 presents the mean values of the measurements, along with the standard deviation (SD).

\subsubsection{Preparation method}

The desired density index of the sand layers was obtained by gently pouring the sand into the container filled with water and then compacting each sand layer by gentle tamping with a flat cylindrical plate (diameter $6.5 \mathrm{~cm}$ ) until a layer thickness of $2.0 \mathrm{~cm}$ was reached. The density index was determined by measuring the height of the soil model during sample preparation and the weight of the sand that had been poured into the water. In this way, saturated soil samples were created.
The Vingerling clay was delivered in bricks. To create clay layers of a certain height, the bricks were cut into slices using a steel wire and carefully laid next to each other to form a continuous layer on the sand surface (see Figure 5). Capillary forces were created at the sand surface level to strengthen it so as to reduce sample disturbance due to placement of the clay slices. Further details of the preparation methods used in this research are reported elsewhere (De Lange et al., 2016; Van der Linden, 2016).

\subsection{Test procedure}

Before testing, the pore pressure filter and transducer of the CPT probe were saturated by maintaining a vacuum pressure for at least $12 \mathrm{~h}$ while immersed in silicone oil. Saturated conditions during the tests were ensured by a water level of a few centimetres above the soil surface level.

In order to obtain a sufficient level of detail, measurements were taken at $1 \mathrm{~mm}$ intervals. The applied data acquisition system had a maximum sampling frequency of $4 \mathrm{~Hz}$, so CPT was performed with a penetration rate of $4 \mathrm{~mm} / \mathrm{s}$ and a sampling frequency of $4 \mathrm{~Hz}$ was applied. Sleeve friction and pore pressure were recorded along with cone resistance.

After performing the CPT, the samples were excavated, visually inspected and photographed with the cone left in place. Samples were also taken in order to determine the local density index. Although the samples taken after testing were affected by the cone penetration, the measurements gave an indication of sample homogeneity.

\subsection{Test results}

\subsubsection{Cone resistance}

Figure 6 shows the cone resistances measured during tests 2, 5, 6 and 7. The layered units, containing $20 \mathrm{~mm}$ thick or $80 \mathrm{~mm}$ thick clay and sand layers, can be clearly distinguished in tests 5 and 6 . The characteristic clay resistance was obtained during penetration of the $300 \mathrm{~mm}$ clay layer in test 2. It should be reiterated that a higher density index was applied in this model than in the other soil models. The observed variation in sand resistance is ascribed to sample heterogeneity. The cause of the sudden decrease in cone resistance at around $0.53 \mathrm{~m}$ depth during test 7 is not known.

Table 1. Sample properties of the relevant tests

\begin{tabular}{llcc} 
& Details of layered unit & Density index, $\boldsymbol{I}_{\mathbf{D}}$ (sand): $\%$ & Comment \\
\hline Test 2 & One $30 \mathrm{~cm}$ clay layer & 92 & Reference test clay \\
Test 5 & Three $80 \mathrm{~mm}$ clay layers & 55 & \\
Test 6 & Ten $20 \mathrm{~mm}$ clay layers & 55 & Reference test sand \\
Test 7 & No layering & 55 &
\end{tabular}




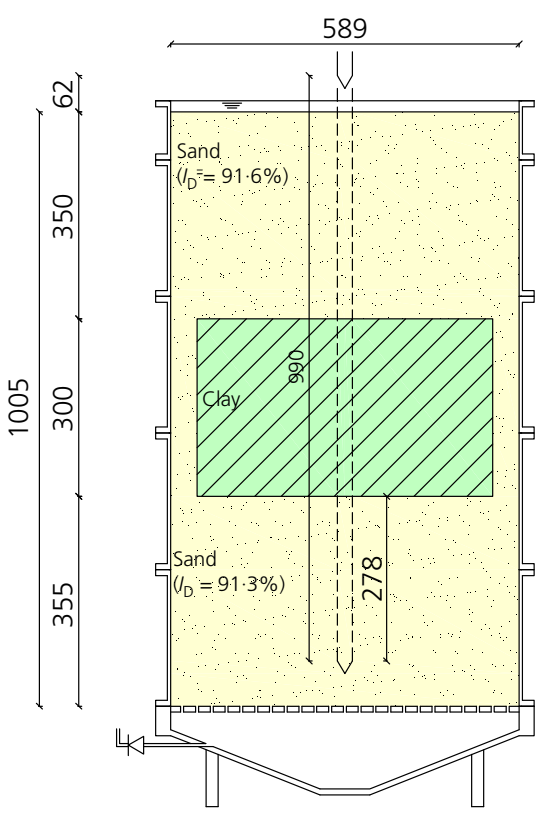

(a)

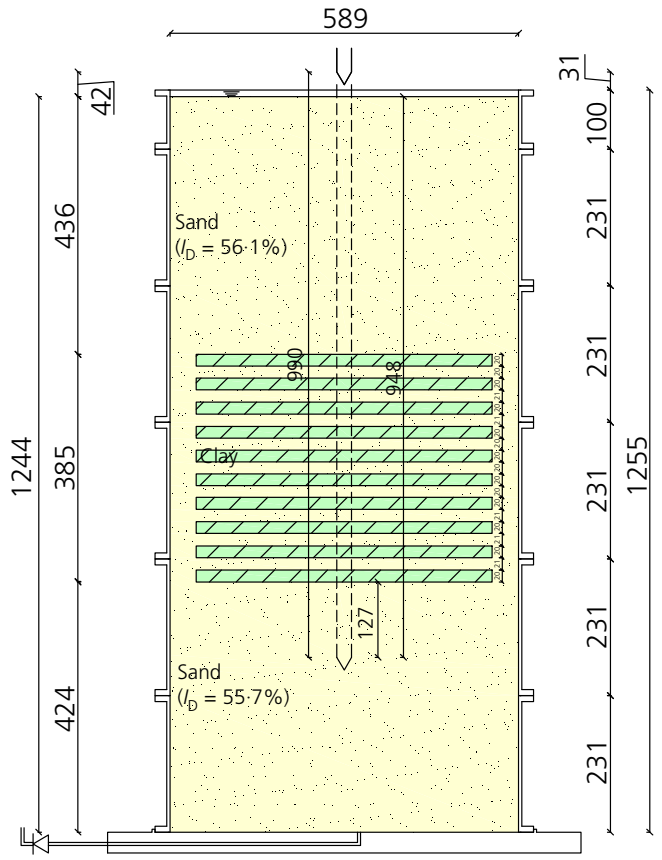

(c)

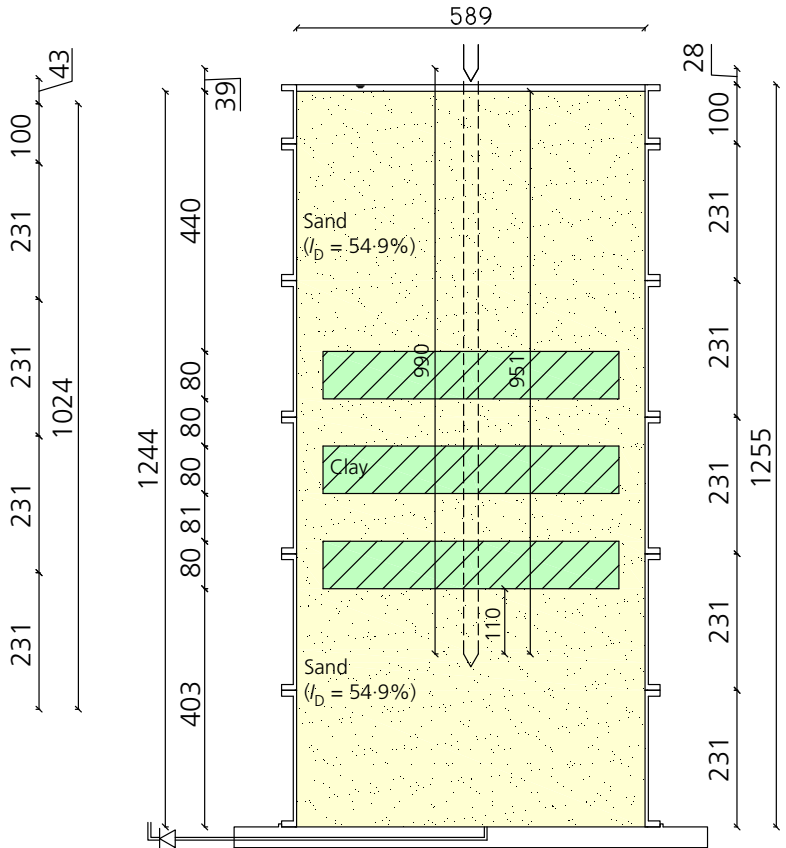

(b)

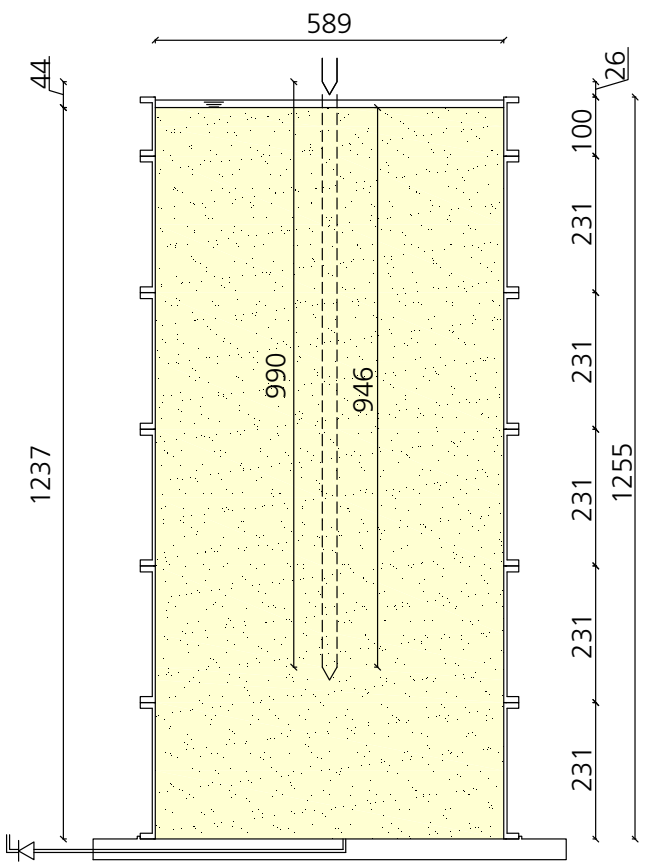

(d)

Figure 4. Test configurations: (a) test 2; (b) test 5; (c) test 6; (d) test 7 (dimensions in $\mathrm{mm}$ )

Table 2. Characteristics of Baskarp sand

\begin{tabular}{|cccc|} 
& $\boldsymbol{d}_{\mathbf{5 0}}: \mathbf{m m}$ & $\boldsymbol{d}_{\mathbf{6 0}} / \boldsymbol{d}_{\mathbf{1 0}}$ & Min-max void ratio: \% \\
\hline Baskarp sand & 0.151 & 1.5 & $55 \cdot 3-89 \cdot 0$
\end{tabular}

Figure 7 shows the results of test 5, performed on the soil model containing $80 \mathrm{~mm}$ thick layers. The results of the reference test (test 7) are included to illustrate the effect of the clay layers. The cone resistance in the $80 \mathrm{~mm}$ sand layers did not fully reach the characteristic resistance of the reference sand. Figure 8 shows the results of test 6 , performed on the soil 
Table 3. Characteristics of Vingerling clay

\begin{tabular}{|llll}
\hline & Undrained shear strength, $\boldsymbol{c}_{\mathbf{u}}: \mathbf{k P a}$ & Water content, $\boldsymbol{w}: \%$ & Plasticity index: \% \\
\hline Vingerling clay & $15(\mathrm{SD}=0 \cdot 5)$ & $24 \%(\mathrm{SD}=0.3 \%)$ & 17
\end{tabular}

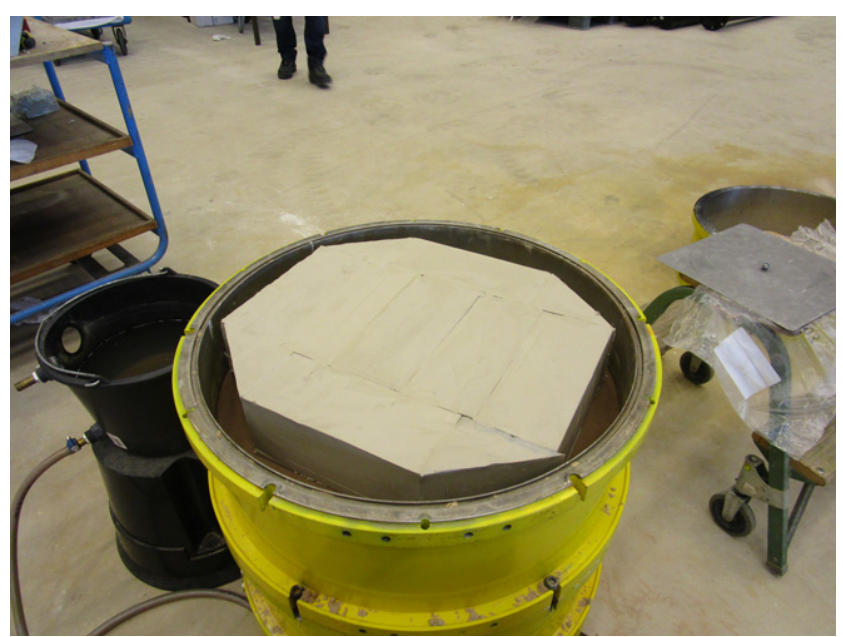

Figure 5. Preparation of clay layers for test 2

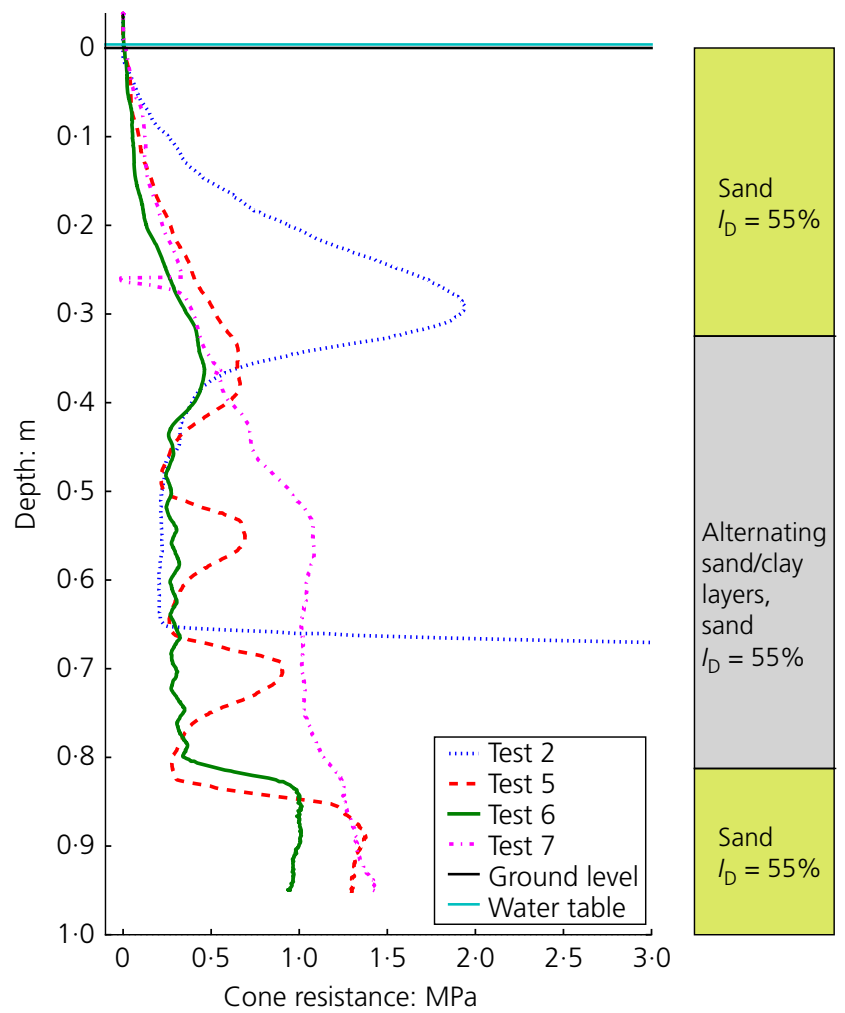

Figure 6. Measured cone resistances; $I_{D}=92 \%$ for test 2 , $I_{D}=55 \%$ for the other tests. A full-colour version of this figure can be found on the ICE Virtual Library (www.icevirtuallibrary.com)

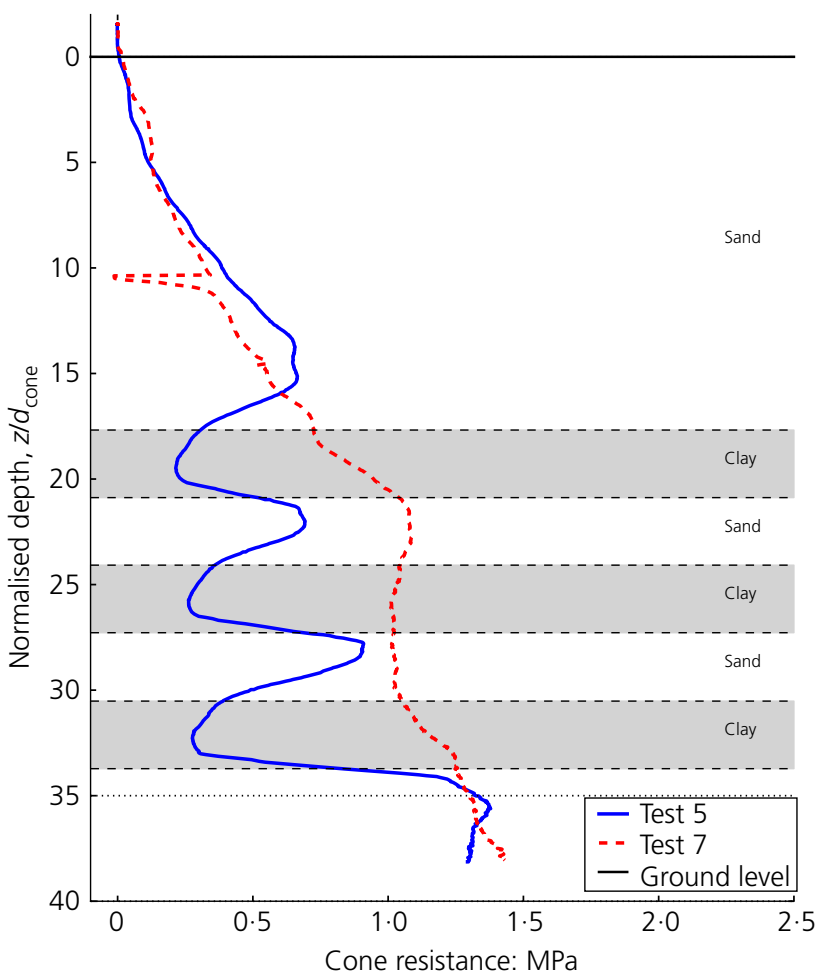

Figure 7. Cone resistance results for test 5 in layered system (three clay layers, each $80 \mathrm{~mm}$ thick) compared with test 7 (reference test, sand only)

model containing $20 \mathrm{~mm}$ thick layers. Although the thin sand layers were still visible, the contrast between the sand and clay layers was relatively small.

The cone resistance of the reference test (test 7) at depths of $0.6-0.8 \mathrm{~m}$ was relatively low compared with the values just above and below this range. It is considered that this zone may have had a lower density index locally due to the sample preparation. This was confirmed by results of density tests on samples taken after CPT. The cone resistance of the sand layer at a depth of $0.7 \mathrm{~m}$ was also found to be denser compared with the other layers, while the bottom sand layer of test 6 seemed to be less dense compared with the bottom sand layers of tests 5 and 7.

From tests 5 and 6 it was observed that the cone resistance started to increase towards the characteristic sand resistance before the cone had passed through the bottom clay layer. It should be noted that the cone shoulder was chosen as the 


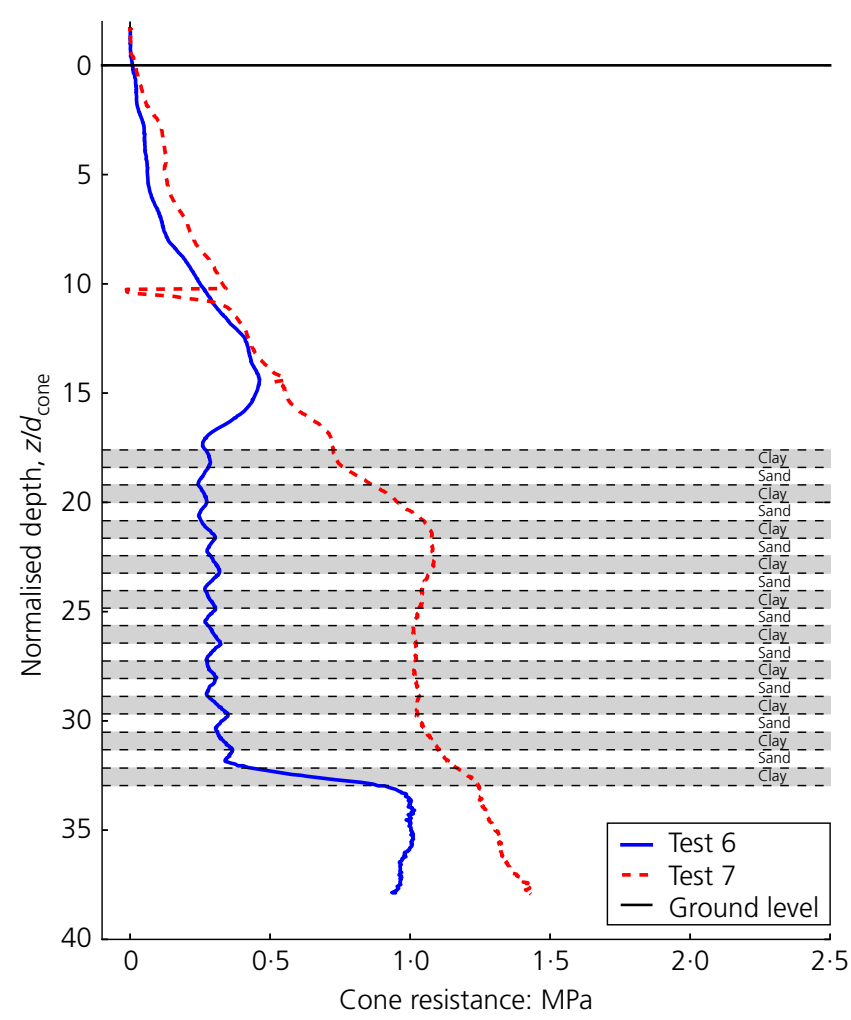

Figure 8. Cone resistance results for test 6 in layered system (ten clay layers, each $20 \mathrm{~mm}$ thick) compared with test 7 (reference test, sand only)

reference level. The distance between the tip and the shoulder was $22 \mathrm{~mm}$. Thus, during test 6 , the cone tip entered the base sand layer before the reference point entered the bottom thin clay layer. Furthermore, since some material was pushed in front of the cone during penetration, the 'sensing level' was lowered.

\subsubsection{Sleeve friction}

Sleeve friction measurements and the corresponding friction ratios are presented in Figures 9 and 10, respectively. The layers of test 5 can be clearly seen in both the sleeve friction and friction ratio plots. However, these measurements did not give a reliable indication of the locations of the layers in test 6 . This is due to the friction sleeve being slightly longer than the thickness of the clay layers in test 5 but considerably longer than the thickness of the clay layers in test 6 , causing the friction sleeve to penetrate multiple layers at the same time. When using soil classification methods like that of Robertson (1990), the resulting classification will be significantly less accurate.

\subsubsection{Pore pressure}

Pore water pressure was measured during penetration by means of the pore pressure transducer. It should be noted that a penetration rate of $4 \mathrm{~mm} / \mathrm{s}$ was applied to obtain data with a high level of detail (the standard rate applied in the field is
$20 \mathrm{~mm} / \mathrm{s}$ ). Results of the pore pressure measurements are presented in Figure 11.

In the bottom sand layer of test 2 (see Figure 11(a)), a decrease in pore pressure was measured, which can be explained by dilative soil behaviour due to the relatively high density index. In all the tests, the increase in pore pressure relative to hydrostatic pressure started after the cone had penetrated the clay a certain distance. This was confirmed by the results of the physical modelling carried out by Van den Berg (1994). This effect is thought to be the result of sand being pushed in front of the cone into the clay layers, as was observed in the dismantled soil samples. Sand intrusions along the cone rod were observed in the clay layers (see Section 4). Pore pressure measurements gave a good indication of the presence of layers of different permeability. However, the thickness of the individual layers could not be determined accurately because of soil disturbance around the cone tip. This confirms the findings of Hird et al. (2003).

\subsubsection{Visual inspection and sampling after CPT}

The soil samples were excavated and photographed after testing. Photographs of tests 5 and 6 are shown in Figure 12, which clearly show that the soil below the cone tip was pushed downwards into the underlying soil layer. These patterns of soil disturbance are comparable to those found by Emmett (2005) during the installation of solid cylindrical piles, although different soil types were used.

To check that the sand layers were uniformly prepared, samples were taken at various depths after CPT to determine the local density. However, since the samples had been disturbed by penetration of the cone, the measurements were only used as indications of local variations and relative differences in the density index of the sand layers.

\section{Analysis of test results}

To quantify the effect of the clay layers on the measured resistance in the intermediate sand layers, a reliable approximation of the characteristic cone resistance in clean sand is needed. However, as mentioned in Section 3, some local variations in density index were observed. Therefore, the expected variation in cone resistance due to variation in density index was calculated based on the methods proposed by Lunne et al. (1997) and Senders (2010). The relationship proposed by Lunne et al. (1997) was used to calculate the clean sand resistance as a function of the vertical effective stress level and the density index, while the formula proposed by Senders (2010) was used to account for the influence of the shallow failure mechanism. Combining these relationships yields

1. $\begin{aligned} q_{\mathrm{c}}= & 61{\sigma_{\mathrm{v}}^{\prime 0.71}}^{0} \exp \left(2 \cdot 91 I_{\mathrm{D}}\right) \\ \times & {\left[1-\exp -\left(\left(\frac{Z}{d_{\text {cone }}}\right)\left(\frac{0.095}{I_{\mathrm{D}}^{2}}\right)\left(\frac{\sigma_{\mathrm{m}}^{\prime}}{p_{\mathrm{a}}}\right)^{0.5}\right)\right] }\end{aligned}$ 


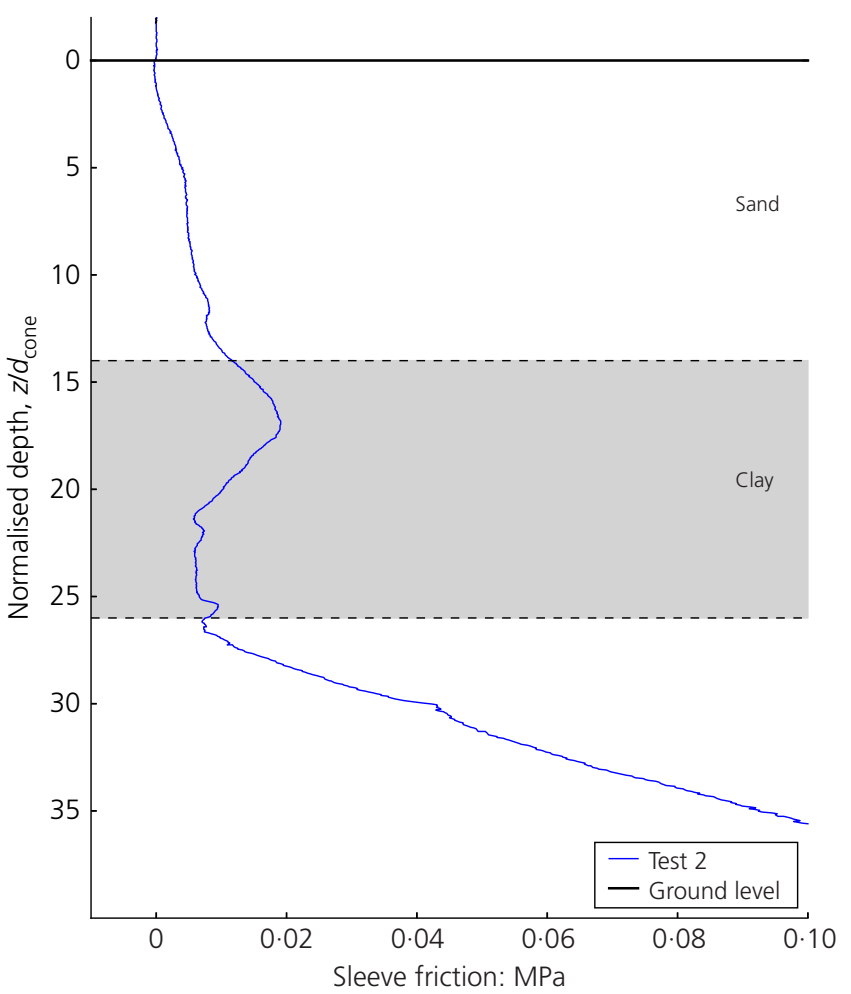

(a)

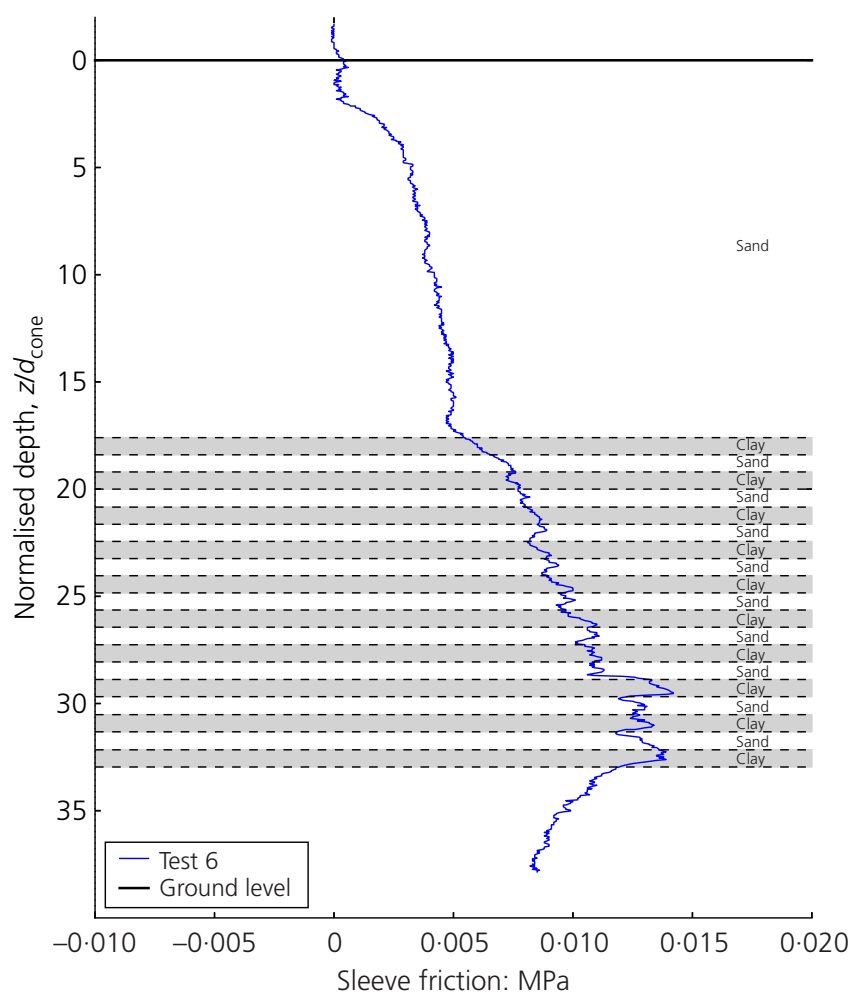

(c)

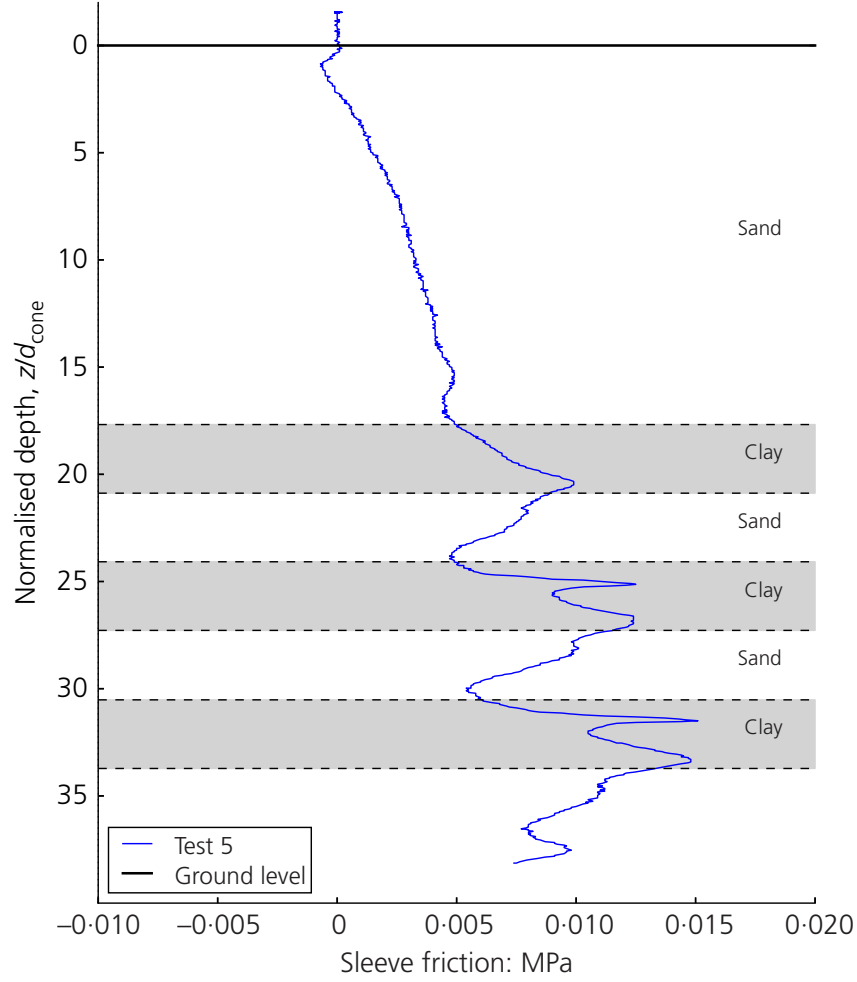

(b)

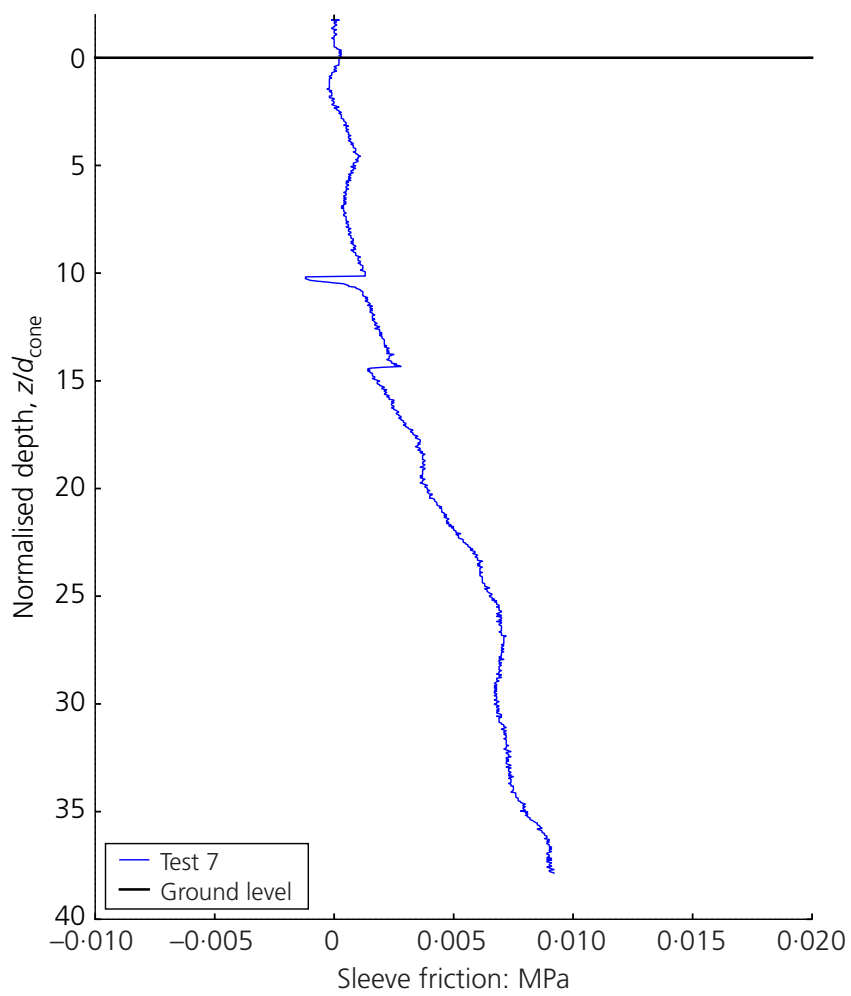

(d)

Figure 9. Results of sleeve friction measurements: (a) test 2 (30 cm clay layer); (b) test 5 (three clay layers, each $80 \mathrm{~mm}$ thick); (c) test 6 (ten clay layers, each $20 \mathrm{~mm}$ thick); (d) test 7 (sand only) 


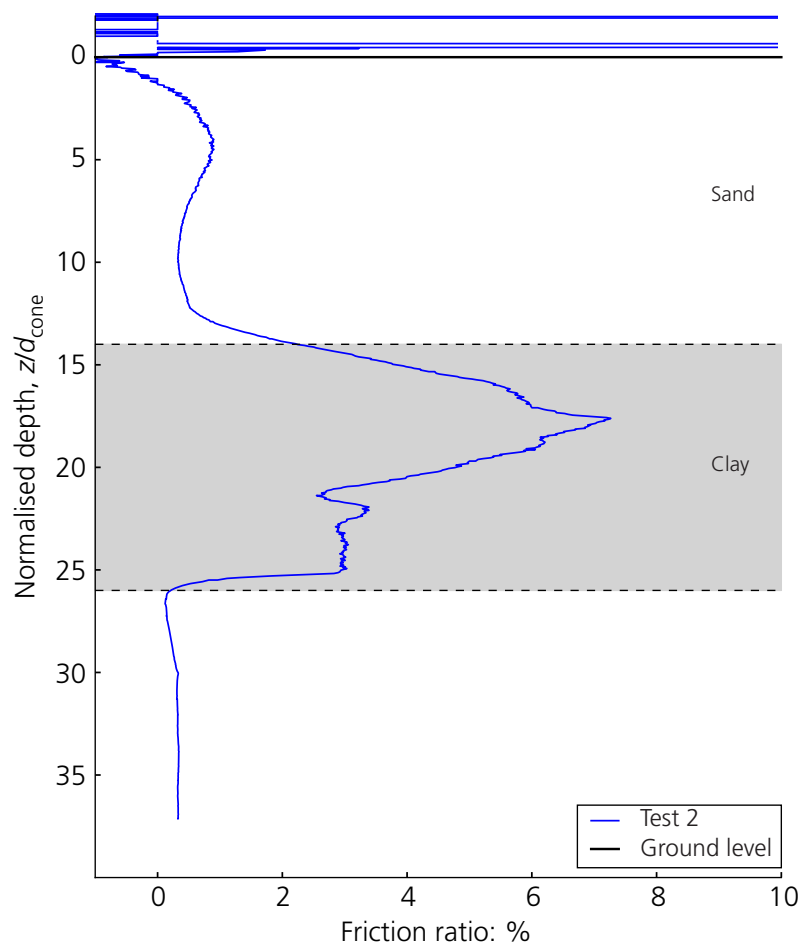

(a)

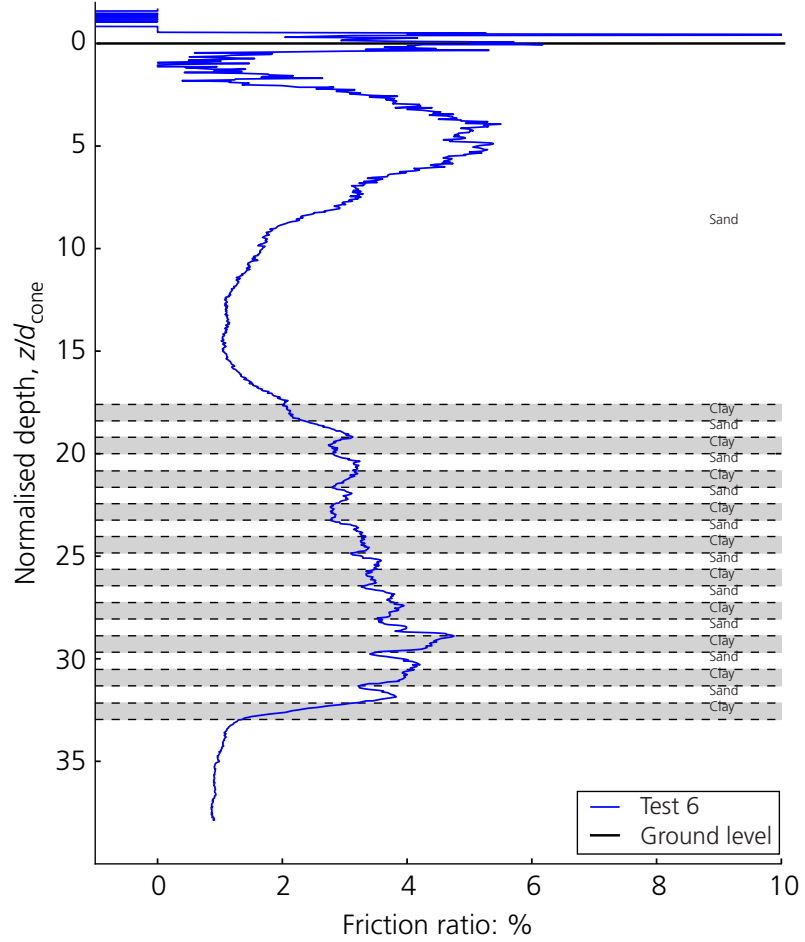

(c)

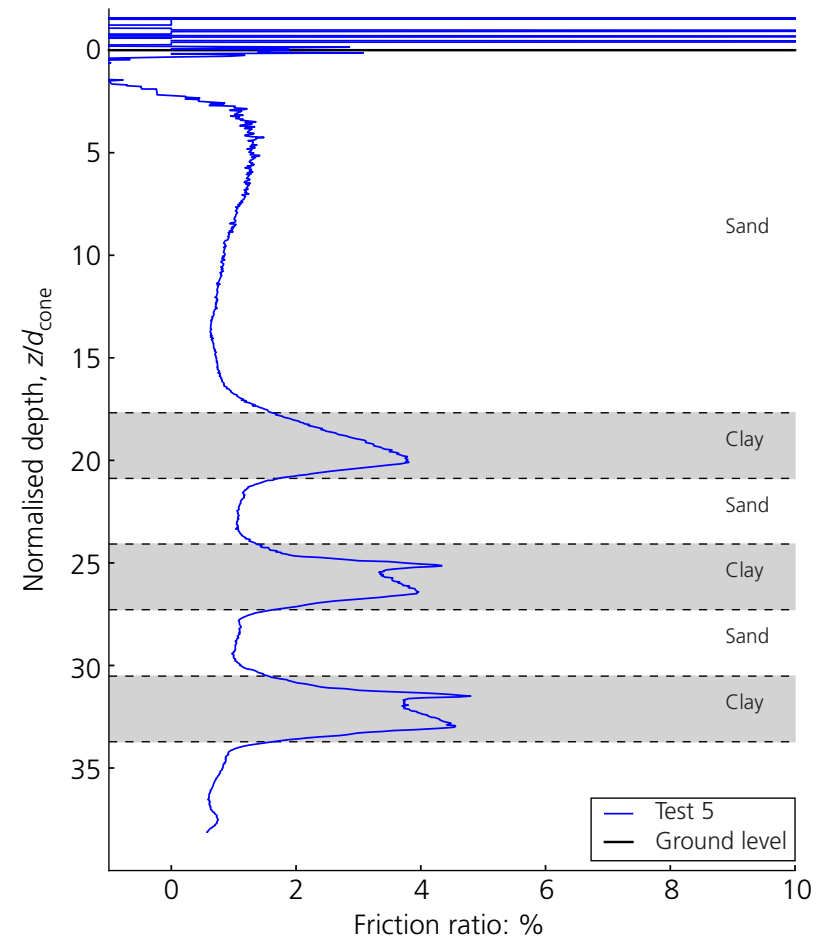

(b)

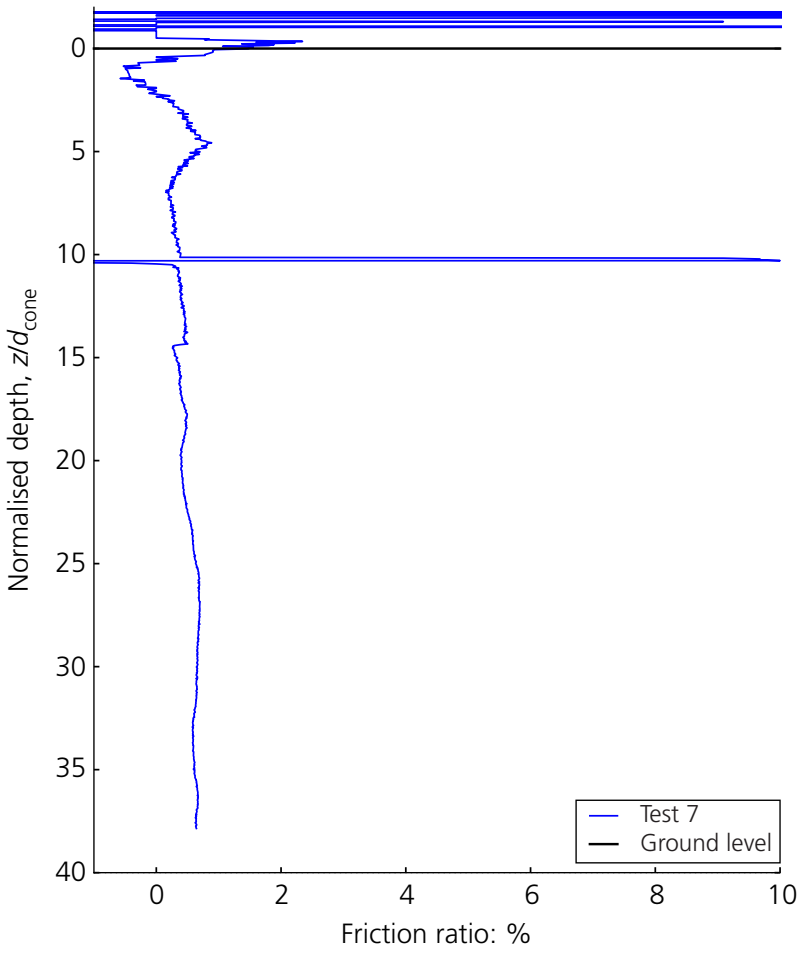

(d)

Figure 10. Friction ratio results: (a) test 2 (30 cm clay layer); (b) test 5 (three clay layers, each $80 \mathrm{~mm}$ thick); (c) test 6 (ten clay layers, each $20 \mathrm{~mm}$ thick); (d) test 7 (sand only) 


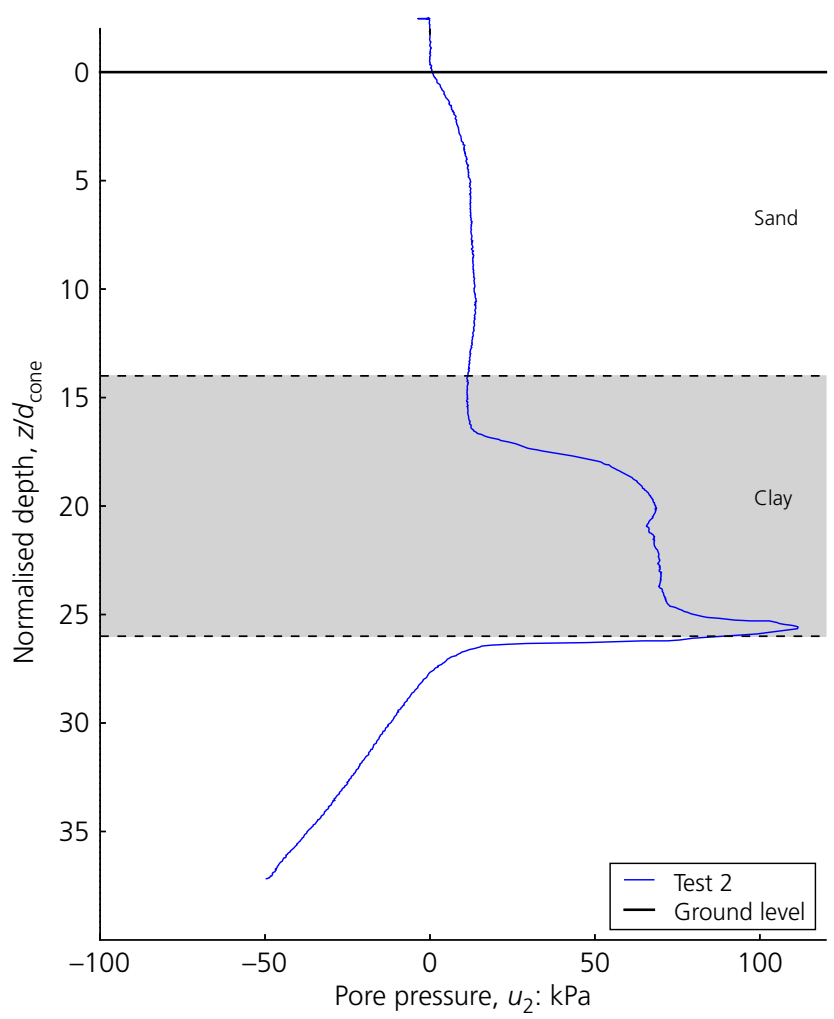

(a)

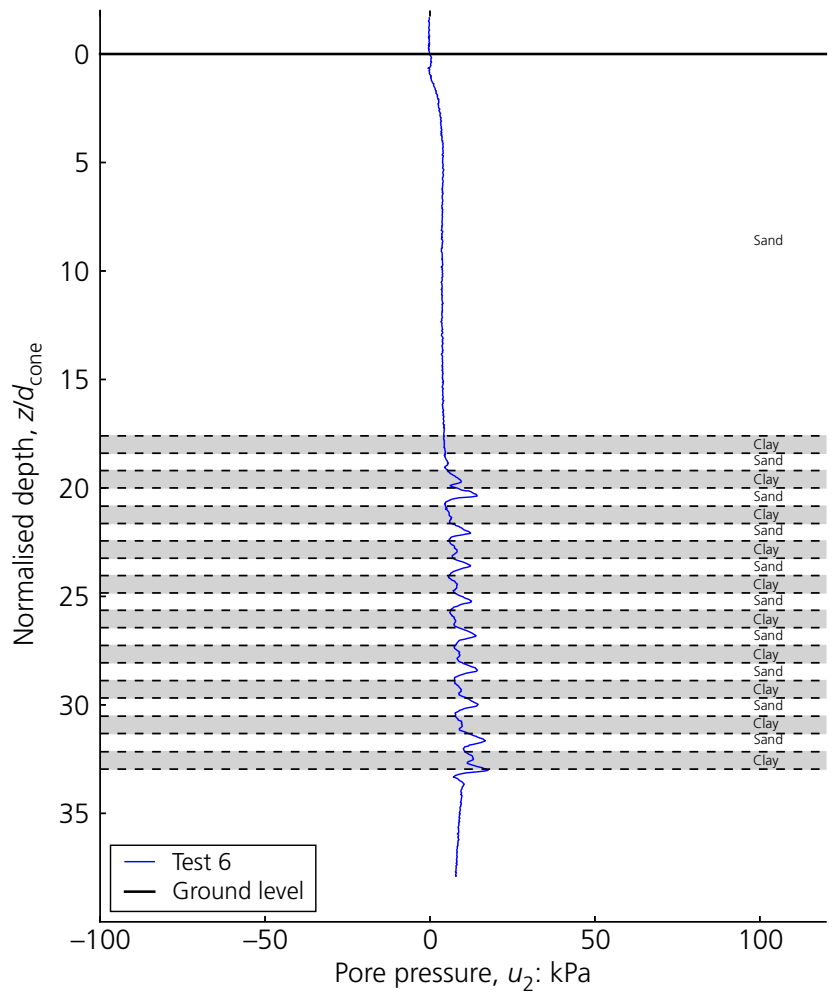

(c)

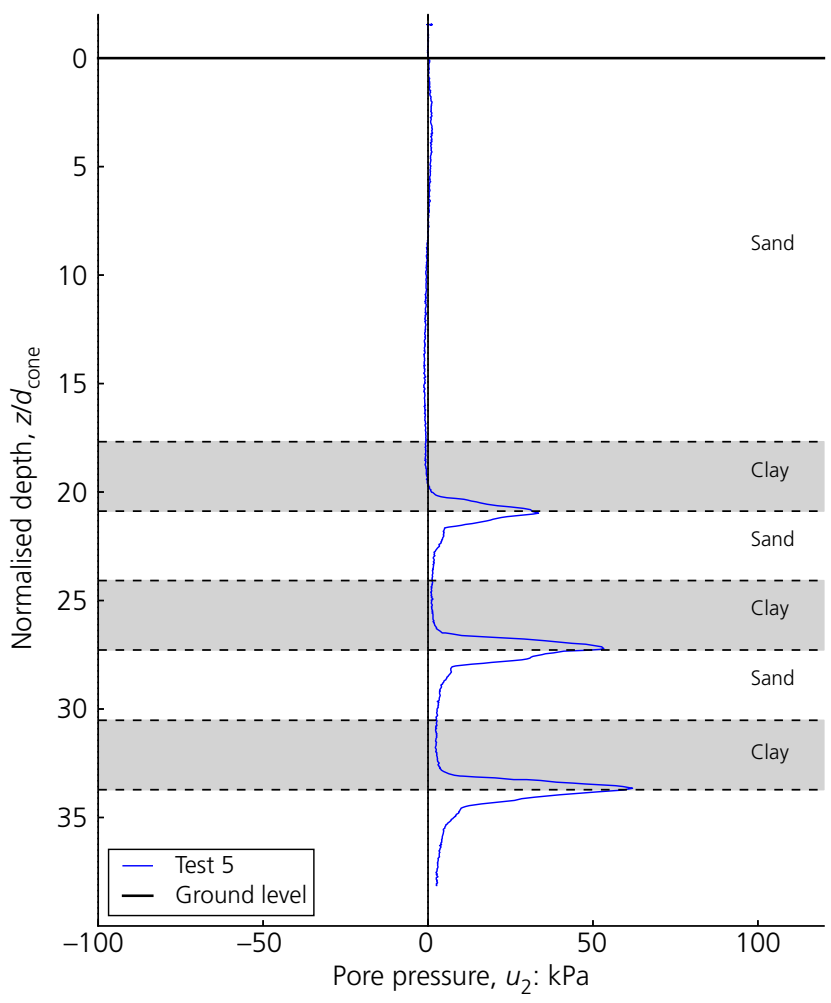

(b)

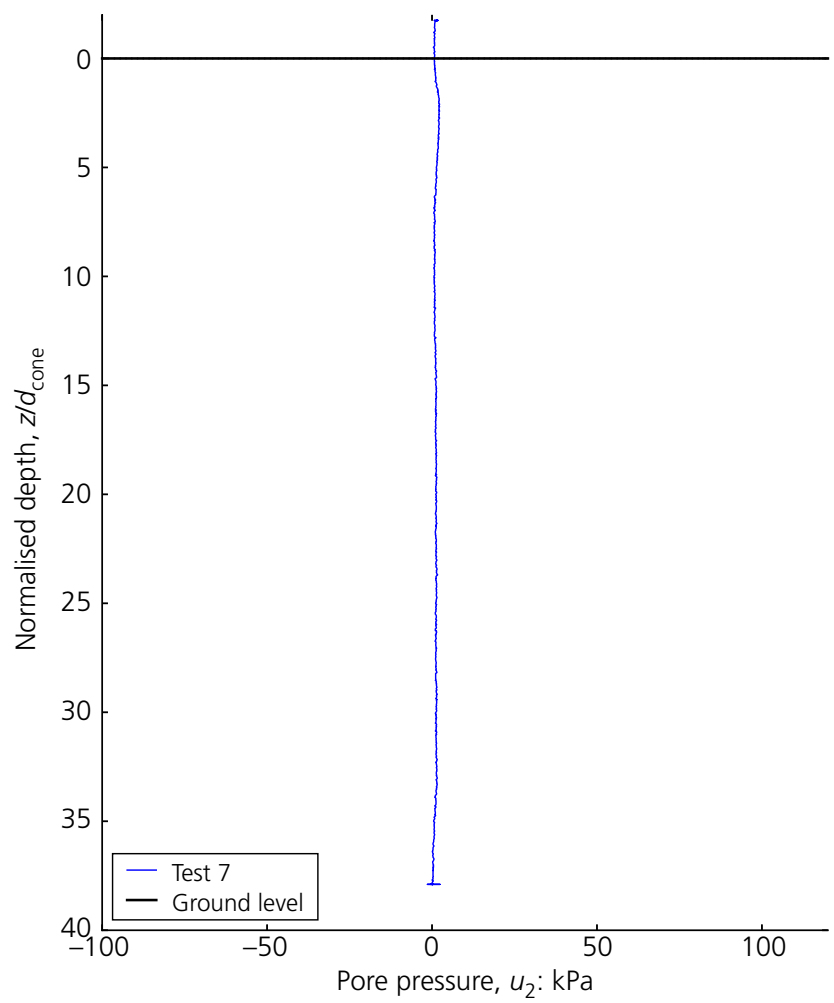

(d)

Figure 11. Results of pore pressure measurements: (a) test 2 (30 cm clay layer); (b) test 5 (three clay layers, each $80 \mathrm{~mm}$ thick); (c) test 6 (ten clay layers, each $20 \mathrm{~mm}$ thick); (d) test 7 (sand only) 


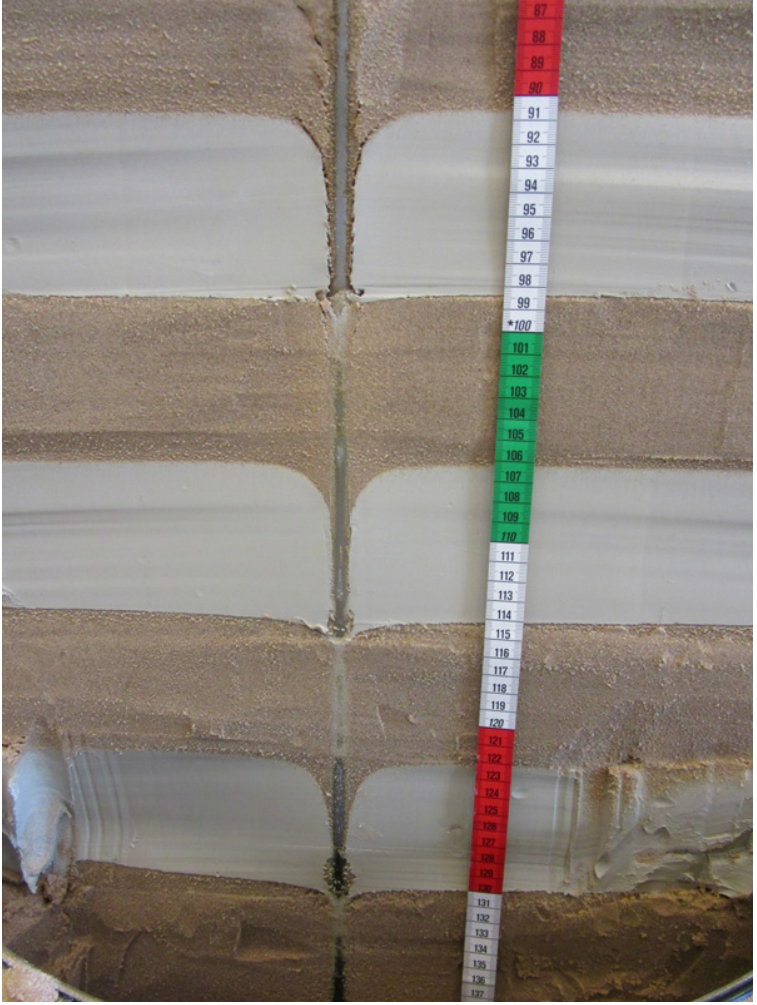

(a)

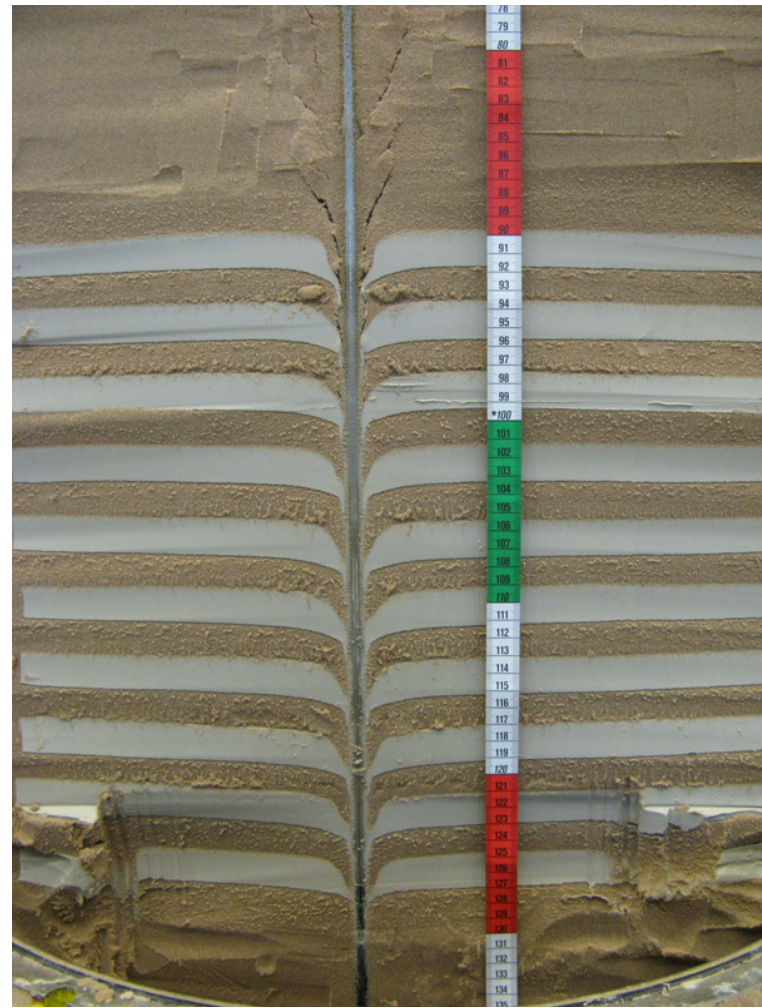

(b)

Figure 12. Excavation along the cone rod after completion of (a) test 5 and (b) test 6

where $\sigma_{\mathrm{v}}^{\prime}$ is the effective vertical stress, $I_{\mathrm{D}}$ is the density index, $Z$ is depth, $d_{\text {cone }}$ is the cone diameter, $p_{\mathrm{a}}$ is atmospheric pressure and $\sigma_{\mathrm{m}}^{\prime}$ is defined as

2. $\sigma_{\mathrm{m}}^{\prime}=\frac{\sigma_{\mathrm{v}}^{\prime}\left(1+2 K_{0}\right)}{3}$

where $K_{0}$ is the coefficient of lateral earth pressure.

The variation in density index was expected to be around $\pm 10 \%$, based on the samples taken after CPT. Figure 13 shows the approximated characteristic cone resistances for sands with a density index of $45 \%, 55 \%$ and $65 \%$. The results of tests 5,6 and 7 are plotted in the same graph. It can be concluded that the formula fits the measured data reasonably.

The correction factor for the sand layers is defined in this research as

3. $K_{\mathrm{t}}=\frac{q_{\mathrm{c}, \text { char,sand }}}{q_{\mathrm{c}, \text { max }, \text { layer }}}$

The theoretical approximations of the characteristic cone resistance for a density index of $45 \%$ and $65 \%$ at a certain stress level were used to determine upper and lower limits of the correction factor for each layer. Correction factors were also derived for a density index of 55\% and based on the data of the reference test (test 7). The correction factors derived for test 6 are plotted in Figure 14. These tended to increase when multiple layers were passed.

The average values of the derived correction factors are plotted in Figure 15 as a function of the normalised layer thickness, $H / d_{\text {cone. }}$ Correction factors higher than 1.5 were found for thin layers when $H / d_{\text {cone }}=0 \cdot 8$, while correction factors lower than $1 \cdot 5$ were found for thicker layers, with $H / d_{\text {cone }}=3 \cdot 2$. It should be noted that correction factors lower than 1 are not realistic.

\section{Comparison with existing analytical models}

Two analytical methods were used to simulate the experimental results: (a) the approach of Vreugdenhil et al. (1994) and (b) the Dutch method (also known as the Koppejan method) for determination of the end bearing capacity of foundation piles. The Dutch method is described in the Dutch annex of Eurocode 7 (NEN 9997-1 (NEN, 2016)).

The 'simple' elastic analysis proposed by Vreugdenhil et al. (1994) was generalised for multiple layers by Joer et al. (1996). 


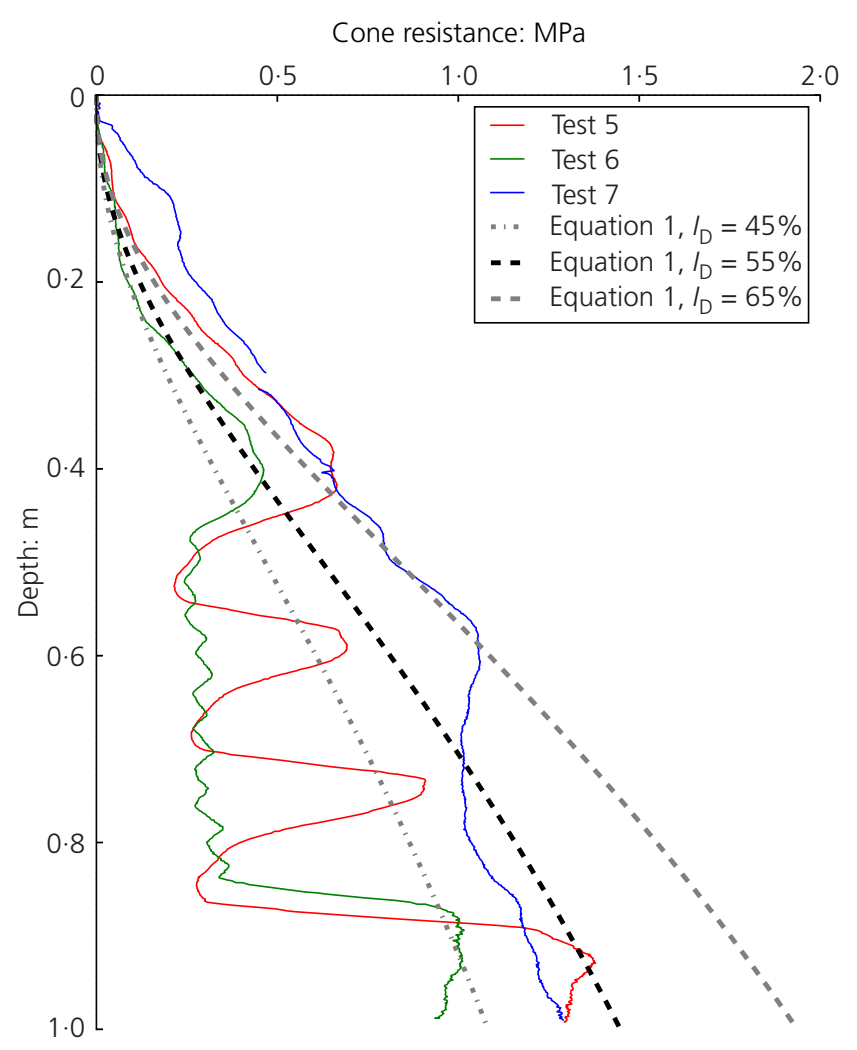

Figure 13. Characteristic cone resistances based on Lunne et al. (1997) and Senders (2010) for sands with a density index of $45 \%$, $55 \%$ and $65 \%$. The results of tests 5, 6 and 7 are also shown. A full-colour version of this figure can be found on the ICE Virtual Library (www.icevirtuallibrary.com)

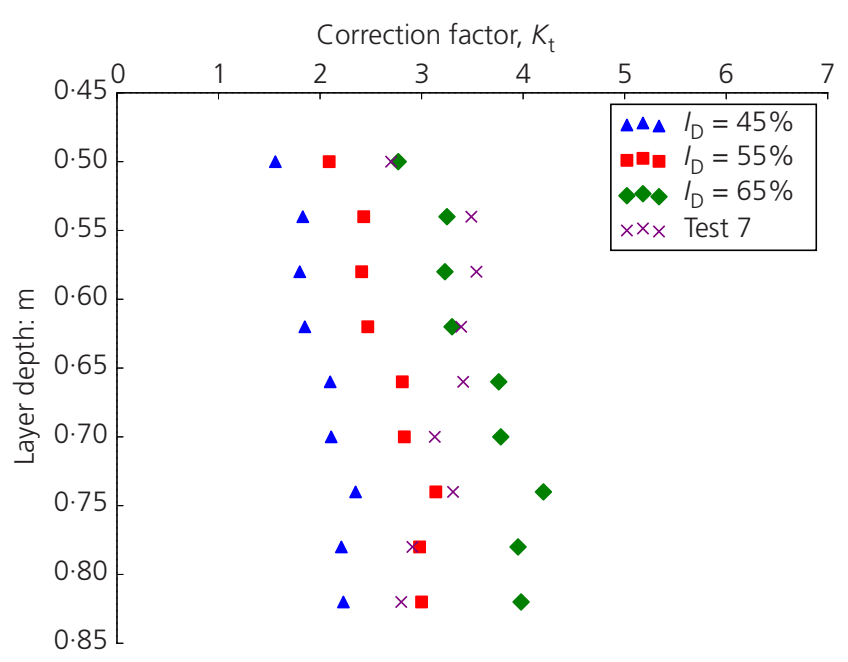

Figure 14. Correction factors derived for test 6 ; multiple values of the characteristic cone resistance were used to account for the observed local variation in density index

This method determines a weighted average of the shear modulus of separate layers, dependent on the cone tip level. The distance to a layer interface determines the degree of

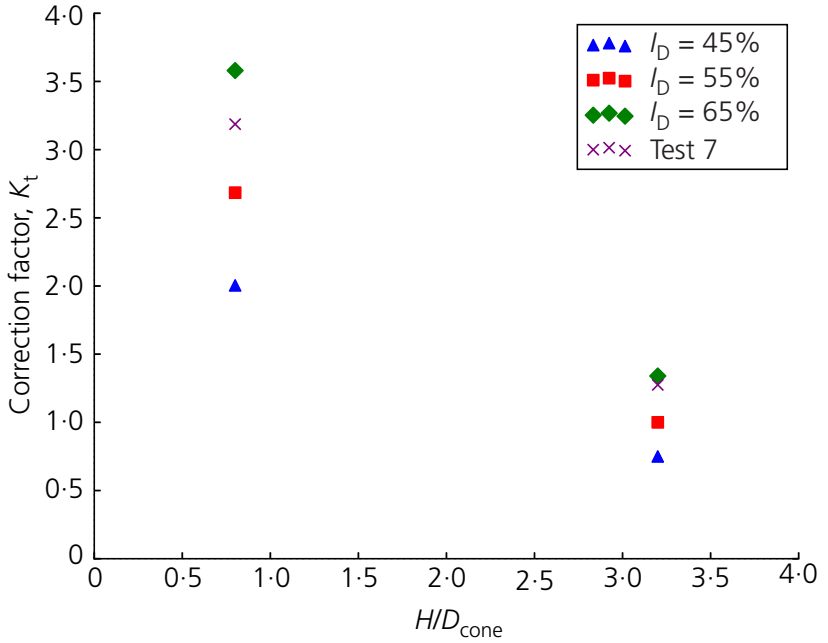

Figure 15. Average of derived correction factors $K_{\mathrm{t}}$ as a function of normalised layer thickness $\mathrm{H} / \mathrm{d}_{\text {cone; }}$ multiple values of the characteristic cone resistance were used to account for the observed local variations in density index

contribution of that layer. The method proposed by Vreugdenhil et al. (1994) assumes that the shear modulus of a layer is proportional to the characteristic cone resistance of that layer, meaning that the relative difference in shear modulus represents the relative difference in characteristic cone resistance.

The Dutch method for determination of the pile base resistance considers the variation of the cone resistance in the range of $4 D_{\text {eq }}$ below and $8 D_{\text {eq }}$ above the base level, $D_{\text {eq }}$ being the equivalent pile diameter. This method was derived from a combination of empirical data and theoretical influence shapes. The procedure of the method is such that a conservative approximation of the path of least resistance will be found. The governing equation is

4. $\quad q_{b, \max }=\frac{1}{2} \alpha_{\mathrm{p}} \beta s\left(\frac{q_{\mathrm{c}, \mathrm{I}, \mathrm{av}}+q_{\mathrm{c}, \mathrm{II}, \mathrm{av}}}{2}+q_{\mathrm{c}, \mathrm{III}, \mathrm{av}}\right)$

where subscripts I, II and III refer to the trajectories for which a governing cone resistance has to be determined by averaging (see Figure 16). The distance below the pile base over which averaging takes place (trajectories I and II) varies between $0 \cdot 7 D_{\text {eq }}$ and $4 D_{\text {eq }}$, depending on the distance over which the minimum value will be met. The procedure to determine the governing cone resistance for trajectories II and III is determined in such a way that the cone resistance taken into account cannot be higher than the cone resistance at deeper levels of these trajectories. The distance above the pile base over which averaging takes place (trajectory III) is fixed at $8 D_{\text {eq. }}$. The parameters $\alpha_{\mathrm{p}}, \beta$ and $s$ represent pile type factors, which were set to 1 for this assessment. 


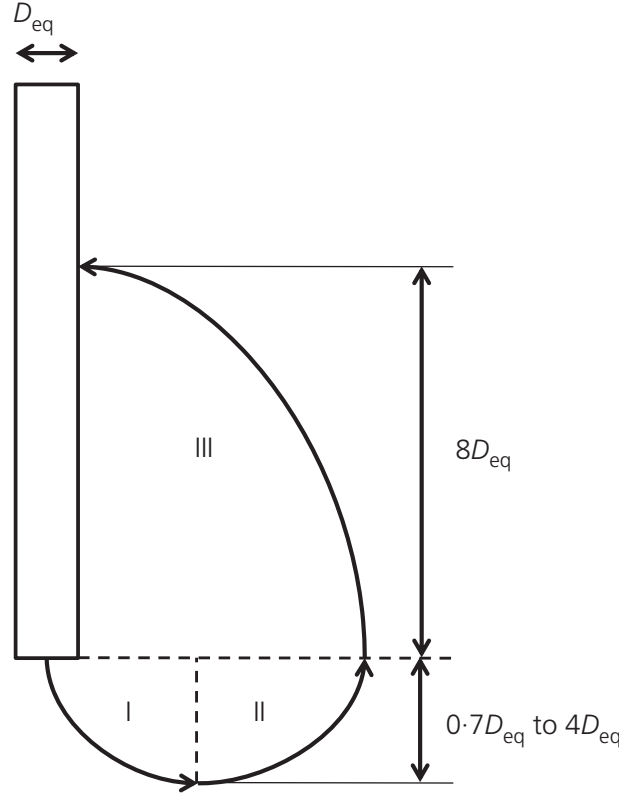

Figure 16. Schematic of the trajectories applied in the Dutch method

Both analytical methods were compared with the results of tests 5 and 6 . The normalised (stress-independent) cone resistance $\left(q_{\mathrm{c}, \text { norm }}\right)$ was used as input to the analytical models. Those values were derived, in line with the work of Lunne et al. (1997), using

5. $\quad q_{c, \text { norm }}=\frac{q_{\mathrm{c}}}{\sigma_{\mathrm{v}}^{\prime 0.71}}$

The results of test 5, 6 and 7, normalised for the in situ effective stress level, are plotted in Figure 17. The characteristic value of the normalised cone resistance of the sand layers with a density index of 55\% was 300 (based on Lunne et al. (1997)) and the characteristic value of the clay layers was 70 , based on the results of test 2 . These characteristic values can be used as input to the analytical models and are also plotted in Figure 17.

The simulations of tests 5 and 6 using both analytical models are shown in Figures 18 and 19, respectively. The simulations using the method of Vreugdenhil et al. (1994) (VM) fit the results of test 5 reasonably well. However, this method seems to be less suitable for thin layers, based on the simulation of test 6 . The individual layers are clearly visible, but the average resistance in the thinly layered part deviated from the actual results of test 6 . Using this elastic method, it seems to be impossible to better the approach of measuring resistance by using the characteristic cone resistance of the individual layers as input. As shown in Figures 18 and 19, the

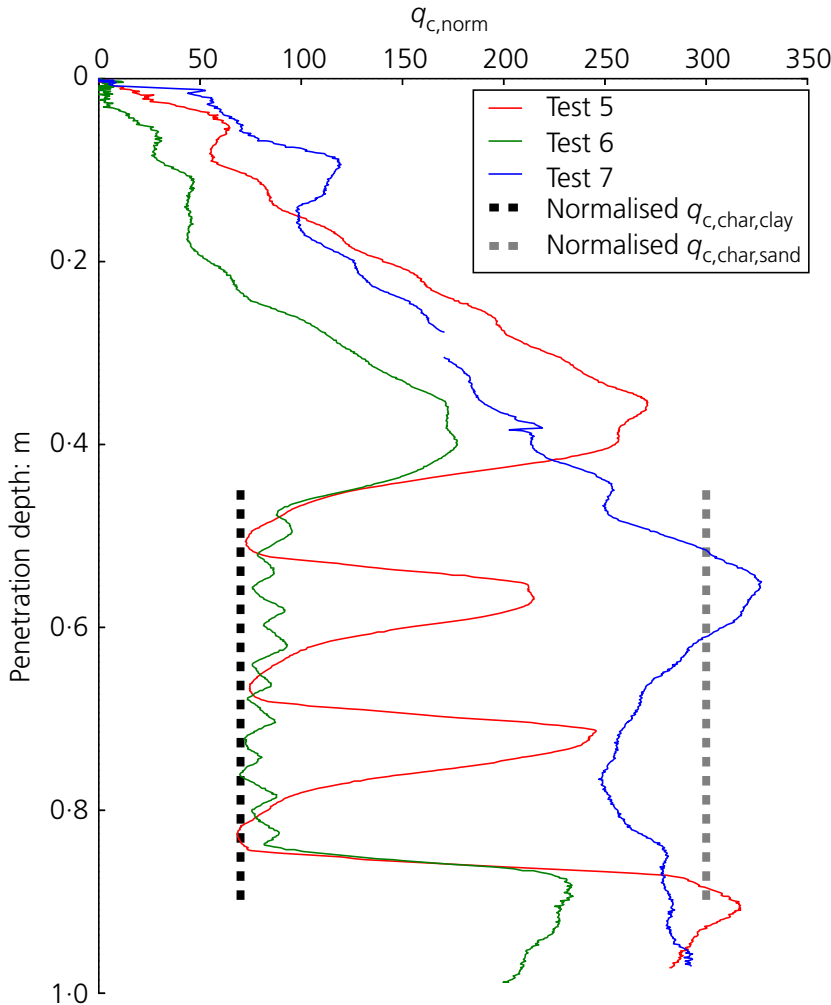

Figure 17. Test results (normalised for stress level) with characteristic values for clay and sand (dashed lines)

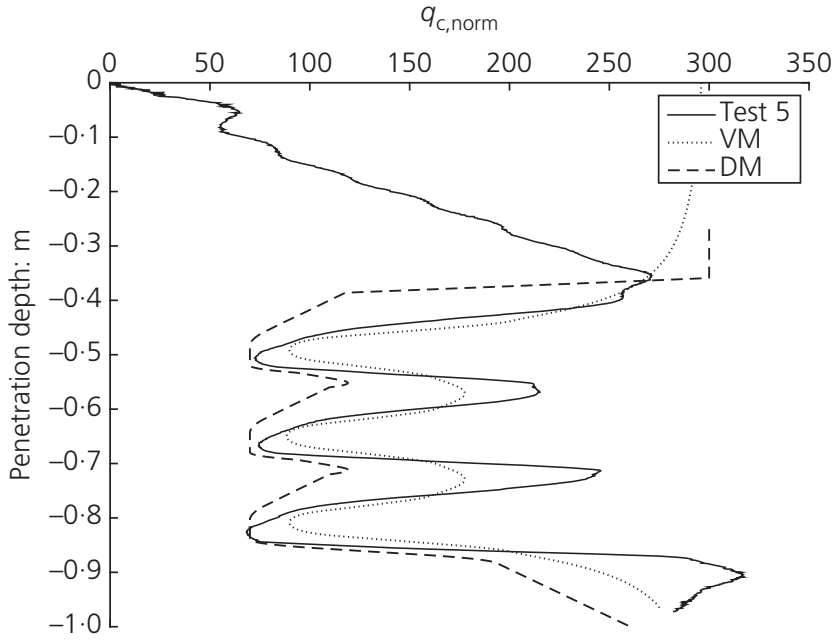

Figure 18. Simulations of test 5

Dutch method (DM) gives a reasonable fit for the clay layers of test 5 and for the thin sand layers of test 6 . However, the method does not appear suitable to predict the resistance of the thicker interbedded sand layers of test 5 . This is because the method was developed to find the lower limit of pile end bearing capacity. 


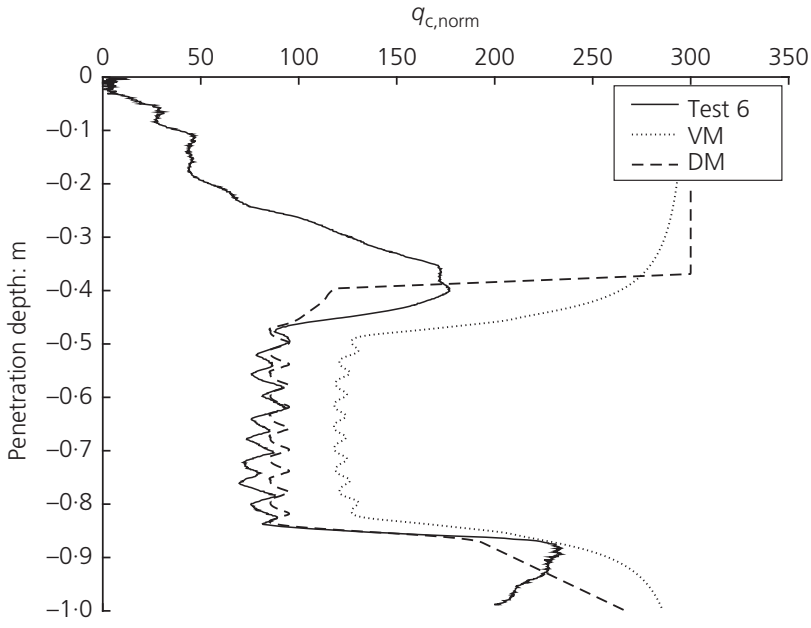

Figure 19. Simulations of test 6

It is believed that the procedure of the Dutch method to determine the governing resistance over trajectories II and III might be the result of the poor fit for test 5 . Therefore, simulations were also carried out where $(a) q_{\mathrm{c}, \text { II }}$ was ignored and $(b)$ both $q_{\mathrm{c}}$, II and $q_{\mathrm{c}, \text { III }}$ were ignored. The results of these simulations are shown in Figure 20. When only the average cone resistance over trajectory I was considered, the Dutch method fitted the results of test 5 well. Simulations using the adapted Dutch method were also been performed for test 6, as shown in Figure 21. However, to find a good fit for the thin layers in test 6 , it seems that it is necessary to take trajectories II and III into account.

Based on these analytical simulations, it was concluded that thin layers require a different approach than thicker

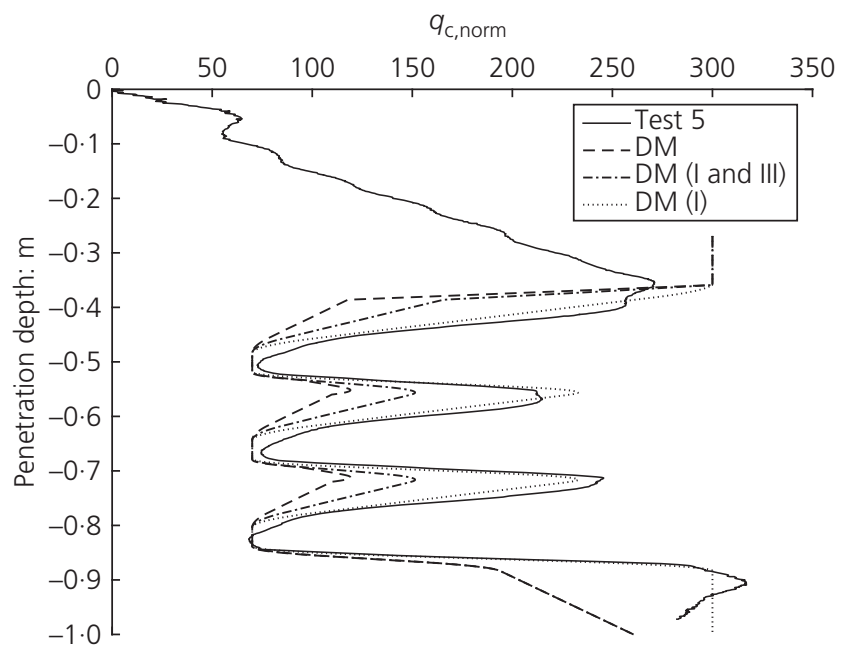

Figure 20. Simulations of test 5 using three variants of the Dutch method - the standard procedure (DM), considering only trajectories I and III (DM (I and III)) and considering only trajectory I (DM (I))

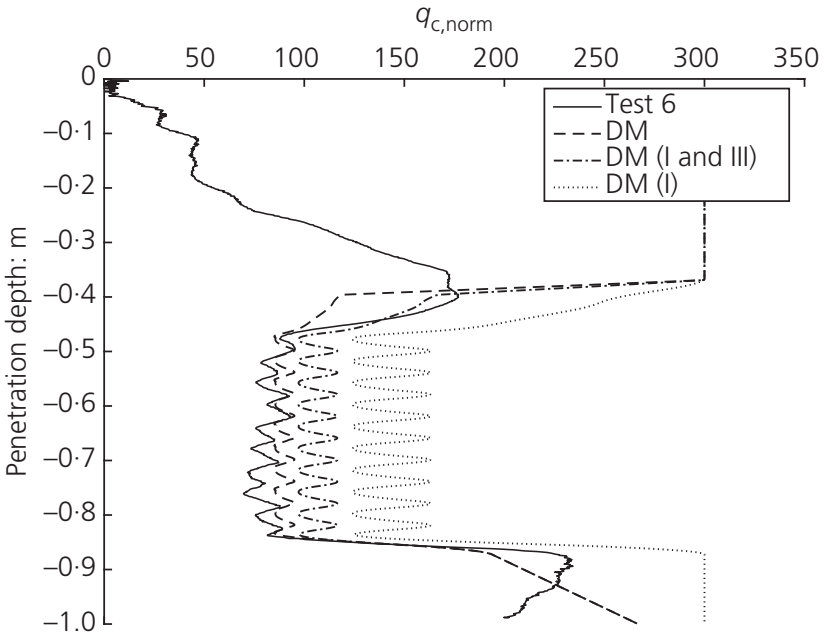

Figure 21. Simulations of test 6 using three variants on the Dutch method - the standard procedure (DM), considering only trajectories I and III (DM (I and III)) and considering only trajectory I (DM (I))

interbedded layers. This is in line with the finding that the magnitude of tip resistance is determined mainly by the dimensions of the failure wedge around the tip (De Beer, 1963). According to Meyerhof (1951), the shape of the failure surface in clays is more spherical and smaller than the shape of the failure surface in sands. The elastic approach of Vreugdenhil et al. (1994) seems to be unsuitable for thinly layered soil deposits.

\section{Suggestions for practical application}

Correction factors can be derived based on validated numerical models. It was concluded from this research that the measured cone resistance is affected by (a) the characteristic resistance of the individual layers, $(b)$ the layer thicknesses relative to the cone diameter and $(c)$ the number of layers within the zone of influence of the cone. Therefore, these aspects should be incorporated in a correction method that can be applied in engineering practice. In the literature, correction factors are given as a function of the normalised layer thickness only and do not take into account the ratio of the characteristics of the individual layers. A possible method, which takes into account this ratio, is given in Figure 22. Based on the layer thickness and the ratio between the maximum resistance measured in a thin sand layer and the minimum resistance measured in the thin surrounding clay layers, a correction factor for the thin sand layer is given. The two lines presented were derived using the Dutch method for the two tested layer configurations $\left(H / d_{\text {cone }}\right.$ ratios of 0.8 and 3.2 and sand and clay layers were of equal thickness). The line representing $H / d_{\text {cone }}=3 \cdot 2$ was derived based on the adapted method, as described earlier, which considers the average cone resistance over trajectory I only. Other lines (for other $H / d_{\text {cone }}$ ratios) could be derived from additional investigations. 


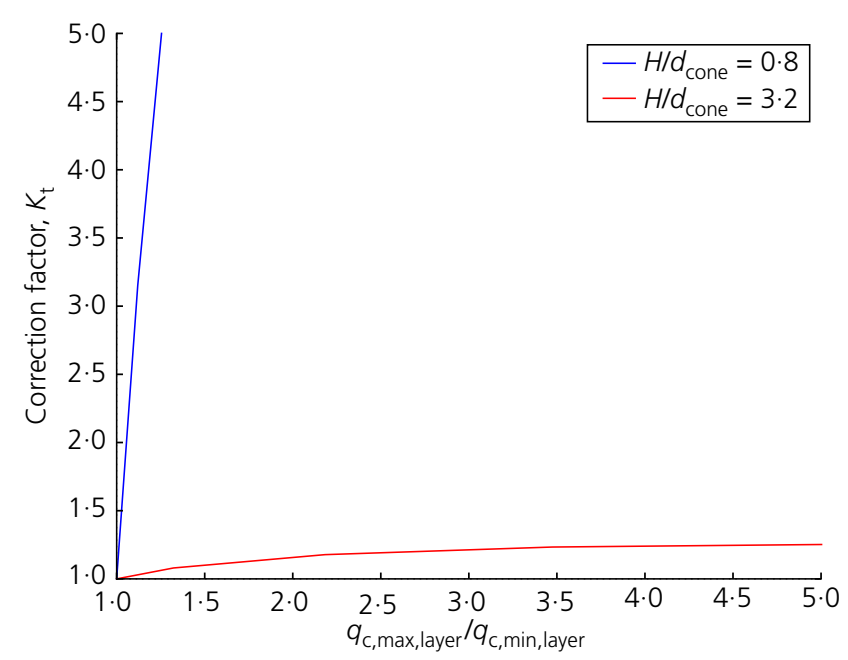

Figure 22. Example of a possible method to correct the measured cone resistance in thinly inter-layered soil deposits

It can be concluded from this research that limited contrast between the cone resistances of sand and clay layers will be seen in thin layers (low $H / d_{\text {cone }}$ ratios). This will cause uncertainty in applying a correction factor: a relatively small difference has relatively large consequences. The use of small cone diameters will reduce the uncertainty. The standard cone has not been developed to deal with thin layers so, in order to determine the layer thickness in the field, boreholes need to be taken with detailed logging of recovered undisturbed samples. A high measuring frequency during CPT is also recommended to obtain a sufficient level of detail.

\section{Discussion}

It should be noted that the penetration rate applied in the experiments $(4 \mathrm{~mm} / \mathrm{s})$ differed from the standard rate applied in the field $(20 \mathrm{~mm} / \mathrm{s})$. Furthermore, the cone resistance was not corrected for the measured pore pressures. However, the effects of both these aspects are considered to be marginal.

Local variation in the void ratio was observed in the artificially constructed soil samples as it was difficult to control the density index during the preparation of saturated layered samples. This aspect was recognised and taken into account in analysis of the test results.

The obtained correction factors do not necessarily apply to soils that experience higher in situ stress levels because the tests presented in this paper were for shallow CPT. In addition, the tested multi-layered samples contained sand and clay layers of equal thickness, but this is certainly not always the case in the field. Therefore, the presented correction factors cannot simply be applied to all thin-layered deposits. Furthermore, only one density index of the interbedded sand layers and one type of clay was applied for preparation of the inter-layered samples. To achieve a sufficient database to validate the numerical method, a comprehensive test programme should be performed to investigate the effects of stress level, density index and layer configuration.

\section{Summary and conclusions}

The results of a feasibility study to propose a correction method for determination of more realistic engineering properties of thin sand layers within thinly inter-layered soils have been presented. Thin layers are defined as layers with a smaller thickness than the diameter of the penetrometer. CPT was performed in artificial deposits containing multiple soil layers. Two different layer thicknesses were investigated and the test results were compared with existing analytical methods.

The experimental test set-up is suitable for investigating multiple thin-layer effects on cone resistance. The cone resistance in thinly inter-layered clay and sand deposits approaches a value slightly higher than the characteristic resistance of the clay layers. Correction factors greater than 1.5 were found for interbedded thin sand layers $\left(H / d_{\text {cone }}=0 \cdot 8\right)$, whereas factors below $1 \cdot 5$ were found for thicker sand layers $\left(H / d_{\text {cone }}=3 \cdot 2\right)$.

The elastic method proposed by Vreugdenhil et al. (1994) seems to be unsuitable for very thinly layered soil deposits, while the Dutch method seems to be able to simulate the cone resistance in such deposits more accurately (NEN, 2016). It is thought that the mechanism in deposits containing multiple thin layers differs from that in deposits containing multiple thicker layers since different approaches were needed to simulate the measurements properly.

It is concluded that the characteristic resistance of the individual layers, the layer thicknesses relative to the cone diameter and the number of layers within the zone of influence of the cone all affect the cone resistance in deposits containing multiple thin soil layers. Suggestions for practical implementation are given in the paper.

\section{Acknowledgements}

The authors would like to acknowledge F. J. M. Hoefsloot and Fugro GeoServices B.V. for their expertise, and for use of the cone and data acquisitioning system. The supervision of M. A. Hicks, A. Askarinejad and R. Stoevelaar is very much appreciated, as is the help of F. M. Schenkeveld and R. Zwaan during physical testing.

\section{REFERENCES}

Ahmadi MM (2000) Analysis of Cone Tip Resistance in Sand. $\mathrm{PhD}$ thesis, University of British Columbia, Vancouver, BC, Canada.

Ahmadi MM and Robertson PK (2004) Calibration chamber size and boundary effects for CPT $q_{\mathrm{c}}$ measurements. In Proceedings of ISC-2 on Geotechnical and Geophysical Site Characterisation (Viana da Fonseca A and Mayne PW (eds)). Millpress, Rotterdam, the Netherlands, pp. 829-833. 
Ahmadi MM and Robertson PK (2005) Thin-layer effects on the CPT $q_{\mathrm{c}}$ measurement. Canadian Geotechnical Journal 42(5): 1302-1317.

Arshad M, Tehrani F, Prezzi M and Salgado R (2014) Experimental study of cone penetration in silica sand using digital image correlation. Géotechnique 64(7): 551-569, http://dx.doi.org/10.1680/geot.13.P.179.

Baldi G, Bellotti R, Ghionna N, Jamiolkowski M and Pasqualini E (1986) Interpretation of CPTs and CPTUs. 2nd Part: drained penetration of sands. Proceedings of the 4th International Geotechnical Seminar, Field Instrumentation and In-Situ Measurements, Nanyang Technological Institute, Singapore, pp. 143-155.

Bolton MD, Gui MW, Laue J et al. (1999) Centrifuge cone penetration tests in sand. Géotechnique 49(4): 543-552, http://dx.doi.org/ 10.1680/geot.1999.49.4.543.

De Beer EE (1963) The scale effect in transportation of the results of deep sounding tests on the ultimate bearing capacity of piles and caissons. Géotechnique 13(1): 39-75, http://dx.doi.org/10.1680/ geot.1963.13.1.39.

De Lange DA, Van Beek VM, Schenkevel FM, Van der Linden TI and Negrinelli G (2016) Preparation techniques for unconventional sand samples. Proceedings of the 3rd European Conference on Physical Modelling in Geotechnics (Eurofuge 2016), Nantes, France (Thorel L, Bretschneider A, Blanc M and Escoffier S (eds)). Institut Français des Sciences et Technologies des Transports, de l'Aménagement et des Réseaux - IFSTTAR, Nantes, France, pp. 61-66.

Emmett KB (2005) Pile disturbance in layered ground. Ground Engineering 38(12): 30-32.

Hird CC, Johnson P and Sills GC (2003) Performance of miniature piezocones in thinly layered soils. Géotechnique 53(10): 885-900, http://dx.doi.org/10.1680/geot.2003.53.10.885.

Idriss IM and Boulanger RW (2008) Soil Liquefaction During Earthquakes. Earthquake Engineering Research Institute, Oakland, CA, USA, Monograph EERI MNO-12.

Joer HA, Randolph MF and Liew YH (1996) Interpretation of cone resistance in layered soils. In Proceedings of the 7th Australia New Zealand Conference on Geomechanics (Jaska MB, Kagawa WS and Cameron DA (eds)). Institution of Engineers, Canberra, Australia, pp. 92-97.

Lunne T, Robertson PK and Powell JJM (1997) Cone Penetration Testing in Geotechnical Practice, 1st edn. Blackie Academic \& Professional, London, UK

Martin AJ (2000) Flaser and wavy bedding in ephemeral streams: a modern and ancient example. Sedimentary Geology 136(1-2): 1-5.

Meyerhof GG (1951) The ultimate bearing capacity of foundations. Géotechnique 2(4): 301-332, http://dx.doi.org/10.1680/geot.1951.2. 4.301 .

Młyranek Z, Gogolik S and Półtorak J (2012) The effects of varied stiffness of soils layers on interpretation of CPTU penetration characteristics. Archives of Civil and Mechanical Engineering 12(2): 253-264.

Mo PQ (2014) Centrifuge Modelling and Analytical Solutions for the Cone Penetration Test in Layered Soils. PhD thesis, The University of Nottingham, Nottingham, UK.

Mo PQ, Marshall AM and Yu HS (2015) Centrifuge modelling of cone penetration tests in layered soils. Géotechnique 65(6): 468-481, http://dx.doi.org/10.1680/geot.14.P.176.

Mo PQ, Marshall AM and Yu HS (2017) Interpretation of cone penetration test data in layered soils using cavity expansion analysis. Journal of Geotechnical and Geoenvironmental Engineering 143(1): 04016084.

NEN (Nederlands Normalisatie-instituut) (2016) NEN 9997-1:2016: Geotechnical design of structures. Part 1: General rules. Nederlands Normalisatie-instituut, Delft, The Netherlands.

Prandtl L (1921) Über die Eindringungsfestigkeit Plastischer Baustoffe und die Festigkeit von Schneiden. Zeitschrift für Angewandte Mathematik und Mechanik 1(1): 15-20 (in German).
Reineck HE and Wunderlich F (1968) Classification and origin of flaser and lenticular bedding. Sedimentology 11(1-2): 99-104.

Robertson PK, Campanella RG, Gillespie D and Greig J (1986) Use of piezometer cone data. In In Situ '86: Use of In-Situ testing in Geotechnical engineering. GSP 6, ASCE, Reston, VA, USA, Specialty Publication, SM 92, pp. 1263-1280.

Robertson PK (1990) Soil classification using the cone penetration test. Canadian Geotechnical Journal 27(1): 151-158.

Robertson PK and Fear CE (1995) Liquefaction and its evaluation. In Proceedings of the 1st International Conference on Earthquake Geotechnical Engineering (Ishihara K (ed.)). Balkema, Rotterdam, the Netherlands, pp. 1253-1289.

Senders M (2010) Cone resistance profiles for laboratory tests in sand. Proceedings of the 2nd International Symposium on Cone Penetration Testing, Huntington Beach, CA, USA (Robertson PK and Mayne PW (eds)), pp. 193-200.

Silva $\mathrm{M}$ and Bolton MD (2004) Centrifuge penetration tests in saturated layered sands. In Proceedings of ISC-2 on Geotechnical and Geophysical Site Characterization (Viana da Fonseca and Mayne (eds)). Millpress, Rotterdam, the Netherlands, pp. 337-384.

Van den Berg P (1994) Analysis of Soil Penetration. PhD thesis, Delft University of Technology, Delft, the Netherlands.

Van den Berg P, De Borst R and Huétink H (1996) An Eulerian finite element model for penetration in layered soil. International Journal for Numerical and Analytical Methods in Geomechanics 20(12): 865-886.

Van der Linden TI (2016) Influence of Multiple Thin Soft Layers on the Cone Resistance in Intermediate Soils. MSc thesis, Delft University of Technology, Delft, The Netherlands.

Vreugdenhil R, Davis R and Berrill J (1994) Interpretation of cone penetration results in multilayered soils. International Journal for Numerical and Analytical Methods in Geomechanics 18(9): 585-599.

Walker J and Yu HS (2010) Analysis of the cone penetration test in layered clay. Géotechnique 60(12): 939-948, http://dx.doi.org/ 10.1680/geot.7.00153.

Xu X (2007) Investigation of the End Bearing Performance of Displacement Piles in Sand. PhD thesis, The University of Western Australia, Perth, Australia.

Xu X and Lehane M (2008) Pile and penetrometer end bearing resistance in two-layered soil profiles. Géotechnique 58(3): 187-197, http://dx.doi.org/10.1680/geot.2008.58.3.187.

Youd TL and Idriss IM (2001) Liquefaction resistance of soils: summary report from the 1996 NCEER and 1998 NCEER/NSF workshops on evaluation of liquefaction resistance of soils. Journal of Geotechnical and Geoenvironmental Engineering 127(4): 297-313.

\section{How can you contribute?}

To discuss this paper, please email up to 500 words to the editor at journals@ice.org.uk. Your contribution will be forwarded to the author(s) for a reply and, if considered appropriate by the editorial board, it will be published as discussion in a future issue of the journal.

Proceedings journals rely entirely on contributions from the civil engineering profession (and allied disciplines). Information about how to submit your paper online is available at www.icevirtuallibrary.com/page/authors, where you will also find detailed author guidelines. 